\title{
TIME-DEPENDENT MATRIX MULTI-FRACTURE OF SiC/SiC CERAMIC-MATRIX COMPOSITES CONSIDERING INTERFACE OXIDATION
}

\author{
LI LONGBIAO \\ College of Civil Aviation, Nanjing University of Aeronautics and Astronautics \\ No.29 Yudao St., Nanjing 210016, PR China \\ E-mail: 1lb451@nuaa.edu.cn
}

Submitted October 4, 2018; accepted January 7, 2019

\begin{abstract}
Keywords: Ceramic-matrix composites (CMCs), Matrix multi-cracking, Time-dependent, Interface oxidation
In this paper, the time-dependent matrix multi-cracking of SiC/SiC ceramic-matrix composites (CMCs) has been investigated considering the fibre/matrix interface oxidation. The time-dependent interface oxidation length and temperature-dependent fibre/matrix interface shear stress in the oxidation and the de-bonded region, the interface de-bonded energy, the fibre and matrix modulus and the matrix fracture energy are considered in the analysis for the micro stress field, the interface debonding criterion and the critical matrix strain energy model. The effects of the fibre volume fraction, the fibre/matrix interface shear stress, the fibre/matrix interface frictional coefficient, the fibre/matrix interface de-bonded energy and the matrix fracture energy on the matrix multi-cracking density and the interface oxidation ratio of SiC/SiC composite are discussed for the different temperatures and oxidation time. The experimental matrix multi-cracking density and fibre/matrix interface oxidation ratio are predicted for unidirectional and mini SiC/SiC composites at different testing temperatures and oxidation time.
\end{abstract}

\section{INTRODUCTION}

Ceramic materials possess high specific strength and a specific modulus at elevated temperatures. But their use as structural components is severely limited due to their brittleness. Continuous fibre-reinforced ceramic-matrix composites (CMCs), by incorporating fibres in the ceramic matrices, not only exploit their attractive high-temperature strength, but also reduce the propensity for catastrophic failure $[1,2,3]$. The environment inside the hot section CMC components is harsh and the composite is typically subjected to complex thermomechanical loading, which can lead to matrix multi-cracking $[4,5]$. These matrix cracks form paths for the ingress of the environment oxidising the fibres and leading to a premature failure $[6,7,8,9,10]$. The density and openings of these cracks depend on the fibre architecture, the fibre/matrix interface bonding intensity, the applied load and the environments [11, 12, 13]. It is important to develop an understanding of the matrix multi-cracking damage mechanisms at elevated temperatures considering the oxidation damage mechanisms. [14]

Many researchers performed experimental and theoretical investigations on the matrix multi-cracking evolution of fibre-reinforced CMCs $[15,16,17,18,19$, 20, 21]. Morscher et al. [22] established the relationships for the stress-dependent matrix cracking of a $2 \mathrm{D} \mathrm{SiC/}$ $\mathrm{SiC}$ composite, which was related to the stress in the load-bearing $\mathrm{SiC}$ matrix. Morscher and Gordon [23] monitored the matrix cracking of a $\mathrm{SiC} / \mathrm{SiC}$ matrix composite using acoustic emission (AE) and electrical resistance (ER). Racle et al. [24] established the relationship between the characteristic time of a $25 \%$ total fatigue lifetime and the beginning of the matrix cracking using AE. However, in the studies mentioned above, the time-dependent matrix multi-cracking of the $\mathrm{SiC} / \mathrm{SiC}$ composite at an elevated temperature considering the interface oxidation has not been investigated.

In this paper, the time-dependent matrix multicracking of a $\mathrm{SiC} / \mathrm{SiC}$ composite has been investigated considering the fibre/matrix interface oxidation. The time-dependent interface oxidation length and temperature-dependent fibre/matrix interface shear stress in the oxidation and de-bonded region, the interface debonded energy, the fibre and matrix modulus and matrix fracture energy are considered in the analysis for the micro stress field, the interface debonding criterion and the critical matrix strain energy model. The effects of the fibre volume fraction, the fibre/matrix interface shear 
stress, the fibre/matrix interface frictional coefficient, the fibre/matrix interface de-bonded energy and the matrix fracture energy on the matrix multi-cracking density and the fibre/matrix interface oxidation ratio of the $\mathrm{SiC} / \mathrm{SiC}$ composite are discussed for the different temperatures and oxidation time. The experimental matrix multi-cracking density and the fibre/matrix interface oxidation ratio for the unidirectional and mini $\mathrm{SiC} / \mathrm{SiC}$ composites at different testing temperatures and oxidation time are predicted.

$$
\sigma_{\mathrm{f}}(z, t, T)=\left\{\begin{array}{l}
\frac{\sigma}{V_{\mathrm{f}}}-\frac{2 \tau_{\mathrm{f}}(T)}{r_{\mathrm{f}}} z, z \in[0, \zeta(T)] \\
\frac{\sigma}{V_{\mathrm{f}}}-\frac{2 \tau_{\mathrm{f}}(T)}{r_{\mathrm{f}}} \zeta(t, T)-\frac{2 \tau_{\mathrm{i}}(T)}{r_{\mathrm{f}}}[z-\zeta(t, T)], z \in\left[\zeta(t, T), l_{\mathrm{d}}(t, T)\right] \\
\sigma_{\mathrm{fo}}+\left[\frac{V_{\mathrm{m}}}{V_{\mathrm{f}}} \sigma_{\mathrm{mo}}-\frac{2 \tau_{\mathrm{f}}(T)}{r_{\mathrm{f}}} \zeta(t, T)-\frac{2 \tau_{\mathrm{i}}(T)}{r_{\mathrm{f}}}\left[l_{\mathrm{d}}(t, T)-\zeta(t, T)\right]\right] \\
\times \exp \left[-\rho \frac{z-l_{\mathrm{d}}(t, T)}{r_{\mathrm{f}}}\right], z \in\left[l_{\mathrm{d}}(t, T), \frac{l_{\mathrm{c}}(t, T)}{2}\right] \\
\sigma_{\mathrm{i}}(z, t, T)=\left\{\begin{array}{l}
2 \frac{V_{\mathrm{f}}}{V_{\mathrm{m}}} \frac{\tau_{\mathrm{f}}(T)}{r_{\mathrm{f}}} z, z \in[0, \zeta(t, T)] \\
2 \frac{V_{\mathrm{f}}}{V_{\mathrm{m}}} \frac{\tau_{\mathrm{f}}(T)}{r_{\mathrm{f}}} \zeta(t, T)+2 \frac{V_{\mathrm{f}}}{V_{\mathrm{m}}} \frac{\tau_{\mathrm{i}}(T)}{r_{\mathrm{f}}}[z-\zeta(t, T)], z \in\left[\zeta(t, T), l_{\mathrm{d}}(t, T)\right] \\
\sigma_{\mathrm{mo}}+\left[2 \frac{V_{\mathrm{f}}}{V_{\mathrm{m}}} \frac{\tau_{\mathrm{f}}(T)}{r_{\mathrm{f}}} \zeta(t, T)+2 \frac{V_{\mathrm{f}}}{V_{\mathrm{m}}} \frac{\tau_{\mathrm{i}}(T)}{r_{\mathrm{f}}}\left[l_{\mathrm{d}}(t, T)-\zeta(t, T)\right]-\sigma_{\mathrm{mo}}\right] \\
\times \exp \left[-\rho \frac{z-l_{\mathrm{d}}(t, T)}{r_{\mathrm{f}}}\right], z \in\left[l_{\mathrm{d}}(t, T), \frac{l_{\mathrm{c}}(t, T)}{2}\right] \\
\frac{\rho}{2}\left[\frac{V_{\mathrm{m}}}{V_{\mathrm{f}}} \sigma_{\mathrm{mo}}-\frac{2 \tau_{\mathrm{f}}(T)}{r_{\mathrm{f}}} \zeta(t, T)-\frac{2 \tau_{\mathrm{i}}(T)}{r_{\mathrm{f}}}\left[l_{\mathrm{d}}(t, T)-\zeta(t, T)\right]\right] \\
\tau_{\mathrm{f}}(T), z \in[0, \zeta(t, T)]
\end{array}\right], z \in\left[l_{\mathrm{d}}(t, T), \frac{l_{\mathrm{c}}(t, T)}{2}\right]
\end{array}\right]
$$

where

$$
\begin{gathered}
\zeta(t, T)=\varphi_{1}(T)\left[1-\exp \left(-\frac{\varphi_{2}(T) t}{b}\right)\right] \\
\tau_{\mathrm{i}}(T)=\tau_{0}+\mu \frac{\left|\alpha_{\mathrm{rf}}(T)-\alpha_{\mathrm{rm}}(T)\right|\left(T_{\mathrm{m}}-T\right)}{A} \\
\tau_{\mathrm{f}}(T)=\tau_{\mathrm{s}}+\mu \frac{\left|\alpha_{\mathrm{rf}}(T)-\alpha_{\mathrm{rm}}(T)\right|\left(T_{\mathrm{m}}-T\right)}{A}
\end{gathered}
$$

$$
\begin{gathered}
\sigma_{\mathrm{fo}}=\frac{E_{\mathrm{f}}(T)}{E_{\mathrm{c}}(T)} \sigma+E_{\mathrm{f}}(T)\left(\alpha_{\mathrm{lc}}-\alpha_{\mathrm{lf}}\right) \Delta T \\
\sigma_{\mathrm{mo}}=\frac{E_{\mathrm{m}}(T)}{E_{\mathrm{c}}(T)} \sigma+E_{\mathrm{m}}(T)\left(\alpha_{\mathrm{lc}}-\alpha_{\mathrm{lm}}\right) \Delta T
\end{gathered}
$$


where $E_{\mathrm{f}}(T), E_{\mathrm{m}}(T)$ and $E_{\mathrm{c}}(T)$ denote the temperaturedependent fibre, matrix and composite elastic modulus, respectively; $\alpha_{\mathrm{rf}}$ and $\alpha_{\mathrm{rm}}$ denote the fibre and matrix radial thermal expansion coefficient, respectively; $\alpha_{1 \mathrm{f}}$, $\alpha_{\mathrm{lm}}$ and $\alpha_{\mathrm{lc}}$ denote the fibre, matrix and composite axial thermal expansion coefficient, respectively; and $\Delta T$ denotes the temperature difference between the fabricated temperature $T_{0}$ and the testing temperature $T_{1}(\Delta T=$ $\left.=T_{1}-T_{0}\right)$.

Time-dependent fibre/matrix interface debonding

The fracture mechanics approach is adopted in the present analysis to determine the fibre/matrix interface de-bonded length. [25]

$\gamma_{\mathrm{d}}(T)=\frac{F}{4 \pi r_{\mathrm{f}}} \frac{\partial w_{\mathrm{f}}(z=0)}{\partial l_{\mathrm{d}}} \frac{1}{2}-\int_{0}^{l_{\mathrm{d}}(t, T)} \tau_{\mathrm{i}}(T) \frac{\partial v(z)}{\partial l_{\mathrm{d}}} d z$

where $F\left(=\pi r_{\mathrm{f}}^{2} / V_{\mathrm{f}}\right)$ denotes the fibre load at the matrix cracking plane; $w_{\mathrm{f}}(z=0)$ denotes the fibre axial displacement at the matrix cracking plane and $v(z)$ denotes the relative displacement between the fibre and the matrix. Based on the fibre and matrix axial stress distribution as described in Equations 1 and 2, the fibre and matrix axial displacements of $w_{\mathrm{f}}(z)$ and $w_{\mathrm{m}}(z)$ can be described using the following equations:

$$
\begin{aligned}
w_{\mathrm{f}}(z)= & \int_{z}^{\frac{l_{\mathrm{c}}(t, T)}{2}} \frac{\sigma_{\mathrm{f}}(z, t, T)}{E_{\mathrm{f}}(T)} d z \\
= & \frac{\sigma}{V_{\mathrm{f}} E_{\mathrm{f}}(T)}\left[l_{\mathrm{d}}(t, T)-z\right]-\frac{\tau_{\mathrm{f}}(T)}{r_{\mathrm{f}} E_{\mathrm{f}}(T)}\left[2 \zeta(t, T) l_{\mathrm{d}}(t, T)-\zeta^{2}(t, T)-z^{2}\right] \\
& -\frac{\tau_{\mathrm{i}}(T)}{r_{\mathrm{f}} E_{\mathrm{f}}(T)}\left[l_{\mathrm{d}}(t, T)-\zeta(t, T)\right]^{2}+\frac{\sigma_{\mathrm{fo}}(T)}{E_{\mathrm{f}}(T)}\left[\frac{l_{\mathrm{c}}(t, T)}{2}-l_{\mathrm{d}}(t, T)\right] \\
& +\frac{r_{\mathrm{f}}}{\rho E_{\mathrm{f}}(T)}\left\{\frac{V_{\mathrm{m}}}{V_{\mathrm{f}}} \sigma_{\mathrm{mo}}(T)-\frac{2 \tau_{\mathrm{f}}(T)}{r_{\mathrm{f}}} \zeta(t, T)-\frac{2 \tau_{\mathrm{i}}(T)}{r_{\mathrm{f}}}\left[l_{\mathrm{d}}(t, T)-\zeta(t, T)\right]\right\} \\
& \times\left\{1-\exp \left[-\rho \frac{l_{\mathrm{c}}(t, T) / 2-l_{\mathrm{d}}(t, T)}{r_{\mathrm{f}}}\right]\right\} \\
w_{\mathrm{m}}(z)= & \int_{z}^{\frac{l_{c}(t, T)}{2}} \frac{\sigma_{\mathrm{m}}(z, t, T)}{E_{\mathrm{m}}(T)} d z \\
= & \frac{V_{\mathrm{f}} \tau_{\mathrm{f}}(T)}{r_{\mathrm{f}} V_{\mathrm{m}} E_{\mathrm{m}}(T)}\left[2 \zeta(t, T) l_{\mathrm{d}}(t, T)-\zeta^{2}(t, T)-z^{2}\right] \\
& +\frac{V_{\mathrm{f}} \tau_{\mathrm{i}}(T)}{r_{\mathrm{f}} V_{\mathrm{m}} E_{\mathrm{m}}(T)}\left[l_{\mathrm{d}}(t, T)-\zeta(t, T)\right]^{2}+\frac{\sigma_{\mathrm{mo}}(T)}{E_{\mathrm{m}}(T)}\left[\frac{l_{\mathrm{c}}(t, T)}{2}-l_{\mathrm{d}}(t, T)\right] \\
& -\frac{r_{\mathrm{f}}}{\rho E_{\mathrm{m}}(T)}\left\{\sigma_{\mathrm{mo}}(T)-2 \frac{V_{\mathrm{f}} \tau_{\mathrm{f}}(T)}{r_{\mathrm{f}} V_{\mathrm{m}}} \zeta(t, T)-2 \frac{V_{\mathrm{f}} \tau_{\mathrm{i}}(T)}{r_{\mathrm{f}} V_{\mathrm{m}}}\left[l_{\mathrm{d}}(t, T)-\zeta(t, T)\right]\right\} \\
& \int_{\mathrm{f}}\left\{1-\exp \left[-\rho \frac{l_{\mathrm{c}}(t, T) / 2-l_{\mathrm{d}}(t, T)}{r_{\mathrm{f}}}\right]\right\}
\end{aligned}
$$


The relative displacement of $v(z)$ between the fibre and the matrix can be described using the following equation:

$$
\begin{aligned}
v(z)= & \left|w_{\mathrm{f}}(z)-w_{\mathrm{m}}(z)\right| \\
= & \frac{\sigma}{V_{\mathrm{f}} E_{\mathrm{f}}(T)}\left[l_{\mathrm{d}}(t, T)-z\right]-\frac{E_{\mathrm{c}}(T) \tau_{\mathrm{f}}(T)}{r_{\mathrm{f}} V_{\mathrm{m}} E_{\mathrm{m}}(T) E_{\mathrm{f}}(T)}\left[2 \zeta(t, T) l_{\mathrm{d}}(t, T)-\zeta^{2}(t, T)-z^{2}\right] \\
& -\frac{E_{\mathrm{c}}(T) \tau_{\mathrm{i}}(T)}{r_{\mathrm{f}} V_{\mathrm{m}} E_{\mathrm{m}}(T) E_{\mathrm{f}}(T)}\left[l_{\mathrm{d}}(t, T)-\zeta(t, T)\right]^{2} \\
& +\frac{r_{\mathrm{f}} E_{\mathrm{c}}(T)}{\rho V_{\mathrm{m}} E_{\mathrm{m}}(T) E_{\mathrm{f}}(T)}\left\{\sigma_{\mathrm{mo}}(T)-2 \frac{\tau_{\mathrm{f}}(T)}{r_{\mathrm{f}}} \zeta(t, T)-2 \frac{\tau_{\mathrm{i}}(T)}{r_{\mathrm{f}}}\left[l_{\mathrm{d}}(t, T)-\zeta(t, T)\right]\right\} \\
& \times\left\{1-\exp \left[-\rho \frac{l_{\mathrm{c}}(t, T) / 2-l_{\mathrm{d}}(t, T)}{r_{\mathrm{f}}}\right]\right\}
\end{aligned}
$$

Substituting $w_{\mathrm{f}}(z=0)$ and $v(z)$ into Equation 9, leads to the following equation:

$$
\begin{aligned}
& \frac{E_{\mathrm{c}}(T) \tau_{\mathrm{i}}^{2}(T)}{r_{\mathrm{f}} V_{\mathrm{m}} E_{\mathrm{m}}(T) E_{\mathrm{f}}(T)}\left[l_{\mathrm{d}}(t, T)-\zeta(t, T)\right]^{2}+\frac{E_{\mathrm{c}}(T) \tau_{\mathrm{i}}^{2}(T)}{\rho V_{\mathrm{m}} E_{\mathrm{m}}(T) E_{\mathrm{f}}(T)}\left[l_{\mathrm{d}}(t, T)-\zeta(t, T)\right] \\
& -\frac{\tau_{\mathrm{i}}(T) \sigma}{V_{\mathrm{f}} E_{\mathrm{f}}(T)}\left[l_{\mathrm{d}}(t, T)-\zeta(t, T)\right]+\frac{2 E_{\mathrm{c}}(T) \tau_{\mathrm{f}}(T) \tau_{\mathrm{i}}(T)}{r_{\mathrm{f}} V_{\mathrm{m}} E_{\mathrm{m}}(T) E_{\mathrm{f}}(T)} \zeta(t, T)\left[l_{\mathrm{d}}(t, T)-\zeta(t, T)\right] \\
& -\frac{r_{\mathrm{f}} \tau_{\mathrm{i}}(T) \sigma}{2 \rho V_{\mathrm{f}} E_{\mathrm{f}}(T)}+\frac{E_{\mathrm{c}}(T) \tau_{\mathrm{f}}^{2}(T)}{r_{\mathrm{f}} V_{\mathrm{m}} E_{\mathrm{m}}(T) E_{\mathrm{f}}(T)} \zeta^{2}(t, T)+\frac{E_{\mathrm{c}}(T) \tau_{\mathrm{f}}(T) \tau_{\mathrm{i}}(T)}{\rho V_{\mathrm{m}} E_{\mathrm{m}}(T) E_{\mathrm{f}}(T)} \zeta(t, T) \\
& -\frac{\tau_{\mathrm{f}}(T) \sigma}{V_{\mathrm{f}} E_{\mathrm{f}}(T)} \zeta(t, T)+\frac{r_{\mathrm{f}} V_{\mathrm{m}} E_{\mathrm{m}}(T) \sigma^{2}}{4 V_{\mathrm{f}}^{2} E_{\mathrm{f}}(T) E_{\mathrm{c}}(T)}-\gamma_{\mathrm{d}}(T)=0
\end{aligned}
$$

Solving Equation 13, the fibre/matrix interface de-bonded length can be determined by the following equation:

$$
l_{\mathrm{d}}(t, T)=\left[1-\frac{\tau_{\mathrm{f}}(T)}{\tau_{\mathrm{i}}(T)}\right] \zeta(t, T)+\frac{r_{\mathrm{f}}}{2}\left[\frac{V_{\mathrm{m}} E_{\mathrm{m}}(T) \sigma}{V_{\mathrm{f}} E_{\mathrm{c}}(T) \tau_{\mathrm{i}}(T)}-\frac{1}{\rho}\right]-\sqrt{\left(\frac{r_{\mathrm{f}}}{2 \rho}\right)^{2}+\frac{r_{\mathrm{f}} V_{\mathrm{m}} E_{\mathrm{m}}(T) E_{\mathrm{f}}(T)}{E_{\mathrm{c}}(T) \tau_{\mathrm{i}}^{2}(T)} \gamma_{\mathrm{d}}(T)}
$$

Time-dependent matrix multi-fracture

The temperature-dependent matrix strain energy can be described using the following equation: [26]

$$
\begin{aligned}
& U_{\mathrm{m}}(t, T)=\frac{1}{2 E_{\mathrm{m}}(T)} \int_{A_{\mathrm{m}}} \int_{0}^{l_{\mathrm{c}}(T)} \sigma_{\mathrm{m}}^{2}(z, t, T) d z d A_{\mathrm{m}} \\
& U_{\mathrm{m}}(t, T)=\frac{A_{\mathrm{m}}}{E_{\mathrm{m}}}\left\{\frac{4}{3}\left(\frac{V_{\mathrm{f}}}{V_{\mathrm{m}}} \frac{\tau_{\mathrm{f}}(T)}{r_{\mathrm{f}}(T)}\right)^{2} \zeta^{3}(t, T)+4\left(\frac{V_{\mathrm{f}}}{V_{\mathrm{m}}} \frac{\tau_{\mathrm{f}}(T)}{r_{\mathrm{f}}}\right)^{2}\left[l_{\mathrm{d}}(t, T)-\zeta(t, T)\right] \zeta^{2}(t, T)\right. \\
& +4\left(\frac{V_{\mathrm{f}}}{r_{\mathrm{f}} V_{\mathrm{m}}}\right)^{2} \tau_{\mathrm{f}}(T) \tau_{\mathrm{i}}(T) \zeta(t, T)\left[l_{\mathrm{d}}(t, T)-\zeta(t, T)\right]^{2} \\
& +\frac{4}{3}\left[\frac{V_{\mathrm{f}}}{V_{\mathrm{m}}} \frac{\tau_{\mathrm{i}}(T)}{r_{\mathrm{f}}}\right]^{2}\left[l_{\mathrm{d}}(t, T)-\zeta(t, T)\right]^{3}+\sigma_{\mathrm{mo}}^{2}\left[\frac{l_{\mathrm{c}}(t, T)}{2}-l_{\mathrm{d}}(t, T)\right] \\
& +\frac{2 r_{\mathrm{f}} \sigma_{\mathrm{mo}}(T)}{\rho}\left[2 \frac{V_{\mathrm{f}}}{V_{\mathrm{m}}} \frac{\tau_{\mathrm{f}}(T)}{r_{\mathrm{f}}} \zeta(t, T)+2 \frac{V_{\mathrm{f}}}{V_{\mathrm{m}}} \frac{\tau_{\mathrm{i}}(T)}{r_{\mathrm{f}}}\left[l_{\mathrm{d}}(t, T)-\zeta(t, T)\right]-\sigma_{\mathrm{mo}}(T)\right] \\
& \times\left[1-\exp \left(-\rho \frac{l_{\mathrm{c}}(t, T) / 2-l_{\mathrm{d}}(t, T)}{r_{\mathrm{f}}}\right)\right]+\frac{r_{\mathrm{f}}}{2 \rho}\left[2 \frac{V_{\mathrm{f}}}{V_{\mathrm{m}}} \frac{\tau_{\mathrm{f}}(T)}{r_{\mathrm{f}}} \zeta(t, T)+2 \frac{V_{\mathrm{f}}}{V_{\mathrm{m}}} \frac{\tau_{\mathrm{i}}(T)}{r_{\mathrm{f}}}\left(l_{\mathrm{d}}(t, T)-\zeta(t, T)\right)-\sigma_{\mathrm{mo}}(T)\right]^{2} \\
& \left.\times\left[1-\exp \left(-2 \rho \frac{l_{\mathrm{c}}(t, T) / 2-l_{\mathrm{d}}(t, T)}{r_{\mathrm{f}}}\right)\right]\right\}
\end{aligned}
$$

where $A_{\mathrm{m}}$ is the cross-section area of the matrix in the unit cell.

When the interface is partially de-bonded, substituting the matrix axial stress in Equation 2 into Equation 
When the interface is completely de-bonded, the matrix strain energy can be described using the following equation:

$$
\begin{aligned}
U_{\mathrm{m}}(t, T)= & \frac{A_{\mathrm{m}}}{E_{\mathrm{m}}}\left\{\frac{4}{3}\left[\frac{V_{\mathrm{f}}}{V_{\mathrm{m}}} \frac{\tau_{\mathrm{f}}(T)}{r_{\mathrm{f}}}\right]^{2} \zeta^{3}(t, T)+4\left[\frac{V_{\mathrm{f}}}{V_{\mathrm{m}}} \frac{\tau_{\mathrm{f}}(T)}{r_{\mathrm{f}}}\right]^{2}\right. \\
& {\left[l_{\mathrm{d}}(t, T)-\zeta(t, T)\right] \zeta^{2}(t, T)+4\left(\frac{V_{\mathrm{f}}}{r_{\mathrm{f}} V_{\mathrm{m}}}\right)^{2}(17) } \\
& \tau_{\mathrm{f}}(T) \tau_{\mathrm{i}}(T) \zeta(t, T)\left[l_{\mathrm{d}}(t, T)-\zeta(t, T)\right]^{2} \\
& \left.+\frac{4}{3}\left[\frac{V_{\mathrm{f}}}{V_{\mathrm{m}}} \frac{\tau_{\mathrm{i}}(T)}{r_{\mathrm{f}}}\right]^{2}\left[l_{\mathrm{d}}(t, T)-\zeta(t, T)\right]^{3}\right\}
\end{aligned}
$$

The critical matrix strain energy of $U_{\text {mcr }}$ can be described using the following equation:

$$
U_{\text {mcr }}(T)=\frac{1}{2} k A_{\mathrm{m}} l_{0} \frac{\sigma_{\mathrm{mocr}}^{2}(T)}{E_{\mathrm{m}}(T)}
$$

where $K(k \in[0,1])$ is the critical matrix strain energy parameter; $l_{0}$ is the initial matrix crack spacing; and $\sigma_{\text {mocr }}(T)$ can be described using the following equation:

$$
\sigma_{\text {mocr }}(T)=\frac{E_{\mathrm{m}}(T)}{E_{\mathrm{c}}(T)} \sigma_{\mathrm{cr}}(T)+E_{\mathrm{m}}(T)\left[\alpha_{\mathrm{lc}}(T)-\alpha_{\mathrm{lm}}(T)\right] \Delta T
$$

where $\sigma_{\mathrm{cr}}(T)$ denotes the temperature-dependent critical stress corresponding to the composite's proportional limit stress defined by the ACK model: [15]

$$
\begin{aligned}
\sigma_{\mathrm{cr}}(T)= & {\left[\frac{6 V_{\mathrm{f}}^{2} E_{\mathrm{f}}(T) E_{\mathrm{c}}^{2}(T) \tau_{\mathrm{i}}(T) \gamma_{\mathrm{m}}(T)}{r_{\mathrm{f}} V_{\mathrm{m}} E_{\mathrm{m}}^{2}(T)}\right]^{1 / 3}-} \\
& -E_{\mathrm{c}}(T)\left[\alpha_{\mathrm{lc}}(T)-\alpha_{\mathrm{lm}}(T)\right] \Delta \mathrm{T}
\end{aligned}
$$

where $\gamma_{\mathrm{m}}(T)$ denotes the temperature-dependent matrix fracture energy.

The matrix multi-cracking evolution can be determined using the following equation:

$$
U_{\mathrm{m}}(\sigma, t, T)=U_{\mathrm{crm}}\left(\sigma_{\mathrm{cr}}, T\right)
$$

\section{RESULTS AND DISCUSSIONS}

The ceramic composite system of $\mathrm{SiC} / \mathrm{SiC}$ is used for the case study and its material properties are given by: $V_{\mathrm{f}}=30 \%, r_{\mathrm{f}}=7.5 \mu \mathrm{m}, E_{\mathrm{f}}=230 \mathrm{GPa}, \gamma_{\mathrm{m}}=15 \mathrm{~J} \cdot \mathrm{m}^{-2}$, $\gamma_{\mathrm{d}}=0.4 \mathrm{~J} \cdot \mathrm{m}^{-2}, \tau_{0}=10 \mathrm{MPa}, \alpha_{\mathrm{rf}}=2.9 \times 10^{-6} \mathrm{~K}^{-1}$ and $\alpha_{\mathrm{lf}}=$ $=3.9 \times 10^{-6} \mathrm{~K}^{-1}$.

The temperature-dependent $\mathrm{SiC}$ matrix elastic modulus of $E_{\mathrm{m}}(T)$ can be described using the following equation: [27]

$E_{\mathrm{m}}(T)=\frac{350}{460}\left[460-0.04 T \exp \left(-\frac{962}{T}\right)\right], T \in[300-1773 \mathrm{~K}]$
The temperature-dependent $\mathrm{SiC}$ matrix axial and radial thermal expansion coefficients of $\alpha_{\operatorname{lm}}(T)$ and $\alpha_{\mathrm{rm}}(T)$ can be described using the following equation, respectively: [27]

$\alpha_{\mathrm{lm}}(T)=\alpha_{\mathrm{rm}}(T)=\left\{\begin{array}{l}-1.8276+0.0178 T-1.5544 \cdot 10^{-5} T^{2} \\ +4.5246 \cdot 10^{-9} T^{3}, T \in[125-1273 \mathrm{~K}] \\ 5.0 \cdot 10^{-6} / \mathrm{K}, T>1273 \mathrm{~K}\end{array}\right.$

The temperature dependent fibre/matrix interface de-bonded energy of $\zeta_{\mathrm{d}}(T)$ and the matrix fracture energy of $\zeta_{\mathrm{m}}(T)$ can be described using the following equations, respectively: [28]

$$
\begin{aligned}
& \gamma_{\mathrm{d}}(T)=\gamma_{\mathrm{d}}^{\mathrm{o}}\left[1-\frac{\int_{T_{\mathrm{o}}}^{T} C_{P}(T) d T}{\int_{T_{\mathrm{o}}}^{T_{\mathrm{m}}} C_{P}(T) d T}\right] \\
& \gamma_{\mathrm{m}}(T)=\gamma_{\mathrm{m}}^{\mathrm{o}}\left[1-\frac{\int_{T_{\mathrm{o}}}^{T} C_{P}(T) d T}{\int_{T_{\mathrm{o}}}^{T_{\mathrm{m}}} C_{P}(T) d T}\right]
\end{aligned}
$$

where $T_{\mathrm{o}}$ denotes the reference temperature; $T_{\mathrm{m}}$ denotes the fabricated temperature; $\gamma_{\mathrm{d}}^{\mathrm{o}}$ and $\gamma_{\mathrm{m}}^{\circ}$ denote the fibre/ matrix interface de-bonded energy and the matrix fracture energy at the reference temperature of $T_{\mathrm{o}}$; and $\mathrm{C}_{\mathrm{P}}(T)$ can be described using the following equation:

$$
\begin{aligned}
& C_{P}(T)=76.337+109.039 \times 10^{-3} T- \\
& -6.535 \times 10^{5} T^{-2}-6.535 \times 10^{-6} T^{2}
\end{aligned}
$$

The effects of the fibre volume fraction, the fibre/ matrix interface shear stress, the fibre/matrix interface frictional coefficient, the fibre/matrix interface debonded energy and the matrix fracture energy on the time-dependent matrix multi-cracking density and the interface oxidation ratio are discussed.

Effect of the fibre volume fraction

The effect of the fibre volume fraction (i.e., $V_{\mathrm{f}}=$ $25 \%, 30 \%$ and $35 \%$ ) on the time-dependent matrix multi-cracking and the fibre/matrix interface oxidation ratio of the $\mathrm{SiC} / \mathrm{SiC}$ composite at $T=873 \mathrm{~K}, 973 \mathrm{~K}$ and $1073 \mathrm{~K}$ for the oxidation time of $t=1 \mathrm{~h}$ and $3 \mathrm{~h}$ are shown in Figure 2.

When $V_{\mathrm{f}}=25 \%$ at $T=873 \mathrm{~K}$ and $t=1 \mathrm{~h}$, the matrix multi-cracking density increases from $\varphi=1.2 / \mathrm{mm}$ at $\sigma_{\mathrm{cr}}=$ $=110 \mathrm{MPa}$ to $\varphi=11.9 / \mathrm{mm}$ at $\sigma_{\text {sat }}=120 \mathrm{MPa}$, and the fibre/ matrix interface oxidation ratio decreases from $\zeta / l_{\mathrm{d}}=6 \%$ to $\zeta / l_{\mathrm{d}}=3.4 \%$; and at $t=3 \mathrm{~h}$, the matrix multi-cracking density increases from $\varphi=0.67 \mathrm{~mm}$ at $\sigma_{\text {cr }}=110 \mathrm{MPa}$ to $\varphi=10.7 / \mathrm{mm}$ at $\sigma_{\text {sat }}=123 \mathrm{MPa}$, and the interface oxidation ratio decreases from $\zeta / l_{\mathrm{d}}=16.6 \%$ to $\zeta / l_{\mathrm{d}}=9.8 \%$. At $T=973 \mathrm{~K}$ and $t=1 \mathrm{~h}$, the matrix multi-cracking density increases from $\varphi=0.24 / \mathrm{mm}$ at $\sigma_{\mathrm{cr}}=104 \mathrm{MPa}$ to $\varphi=$ $=9.2 / \mathrm{mm}$ at $\sigma_{\text {sat }}=133 \mathrm{MPa}$, and the interface oxidation ratio decreases from $\zeta / l_{\mathrm{d}}=16.7 \%$ to $\zeta / l_{\mathrm{d}}=9.5 \%$; and at 
$t=3 \mathrm{~h}$, the matrix multi-cracking density increases from $\varphi=0.17 / \mathrm{mm}$ at $\sigma_{\text {cr }}=104 \mathrm{MPa}$ to $\varphi=7.4 / \mathrm{mm}$ at $\sigma_{\text {sat }}=$ $=140 \mathrm{MPa}$, and the interface oxidation ratio decreases from $\zeta / l_{\mathrm{d}}=40.5 \%$ to $\zeta / l_{\mathrm{d}}=25.1 \%$. At $T=1073 \mathrm{~K}$ and

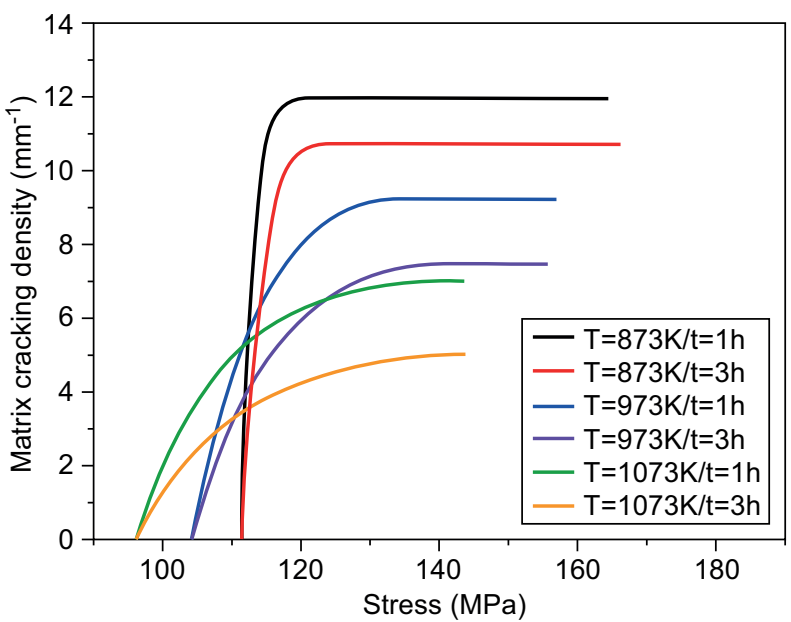

a) $V_{\mathrm{f}}=25 \%$

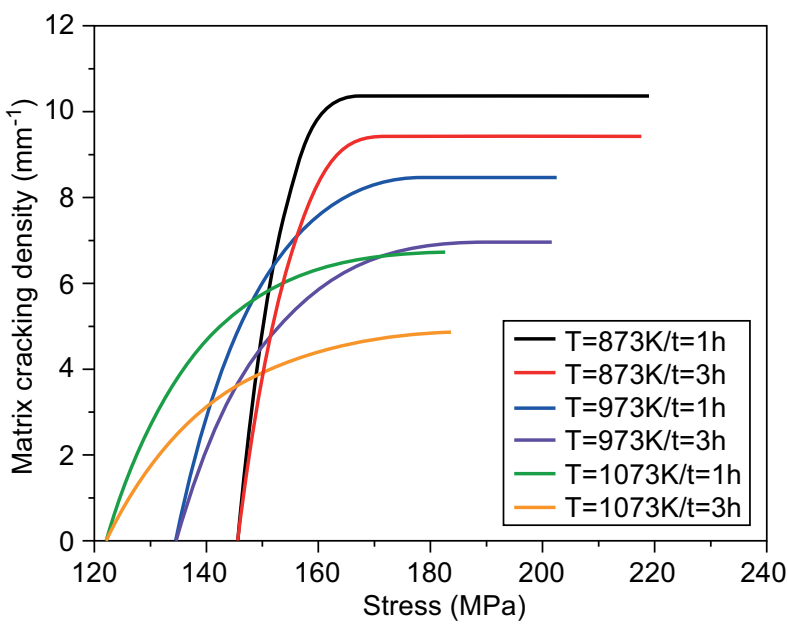

c) $V_{\mathrm{f}}=30 \%$

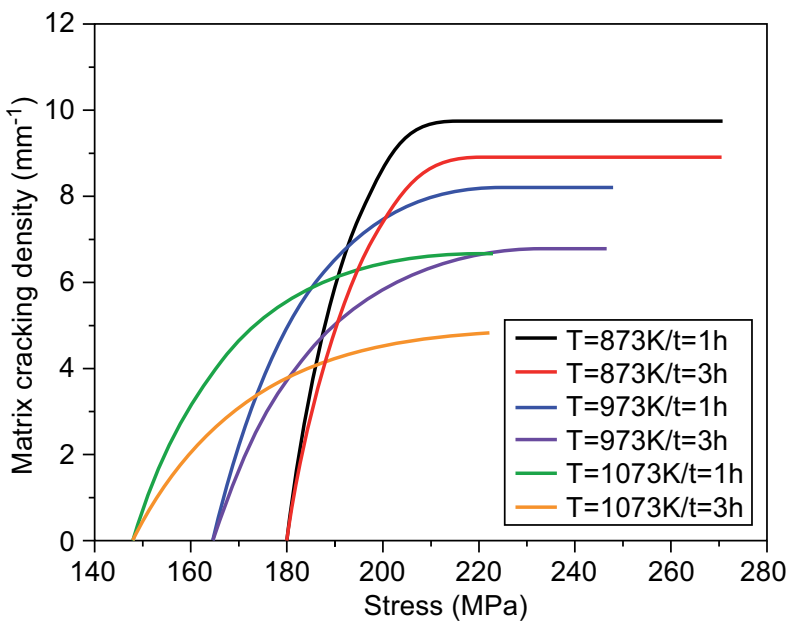

e) $V_{\mathrm{f}}=35 \%$ $t=1 \mathrm{~h}$, the matrix multi-cracking density increases from $\varphi=0.15 / \mathrm{mm}$ at $\sigma_{\text {cr }}=96 \mathrm{MPa}$ to $\varphi=7 / \mathrm{mm}$ at $\sigma_{\text {sat }}=144 \mathrm{MPa}$, and the interface oxidation ratio decreases from $\zeta / l_{\mathrm{d}}=$ $=6.7 \%$ to $\zeta / l_{\mathrm{d}}=21.1 \%$; and at $t=3 \mathrm{~h}$, the matrix multi-

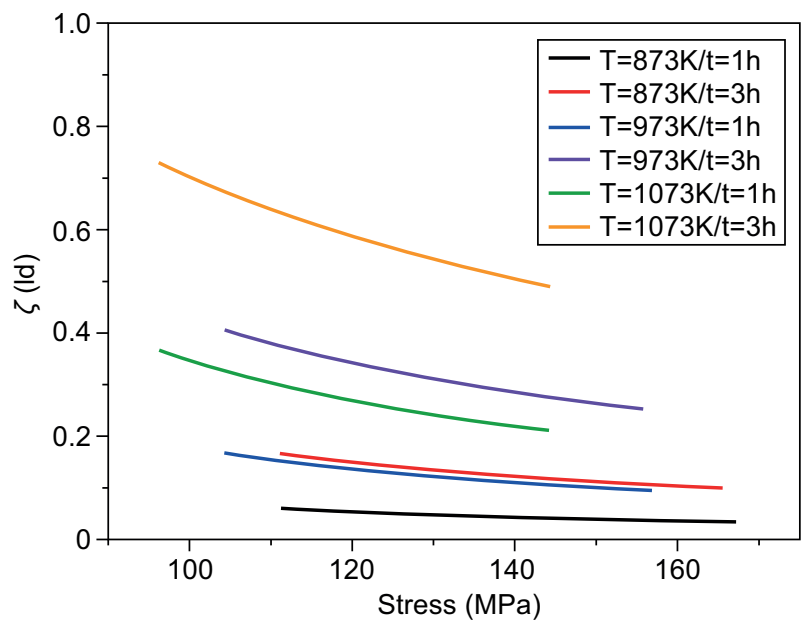

b) $V_{\mathrm{f}}=25 \%$

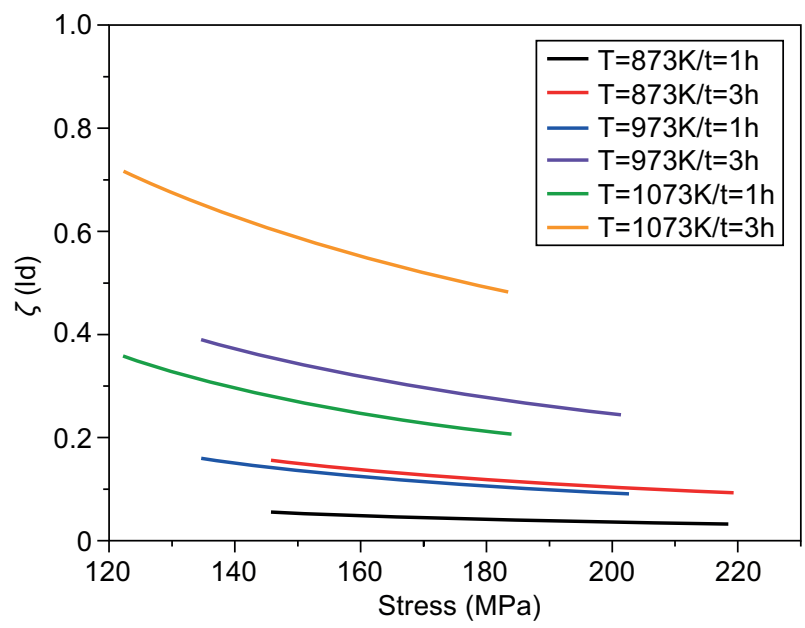

d) $V_{\mathrm{f}}=30 \%$

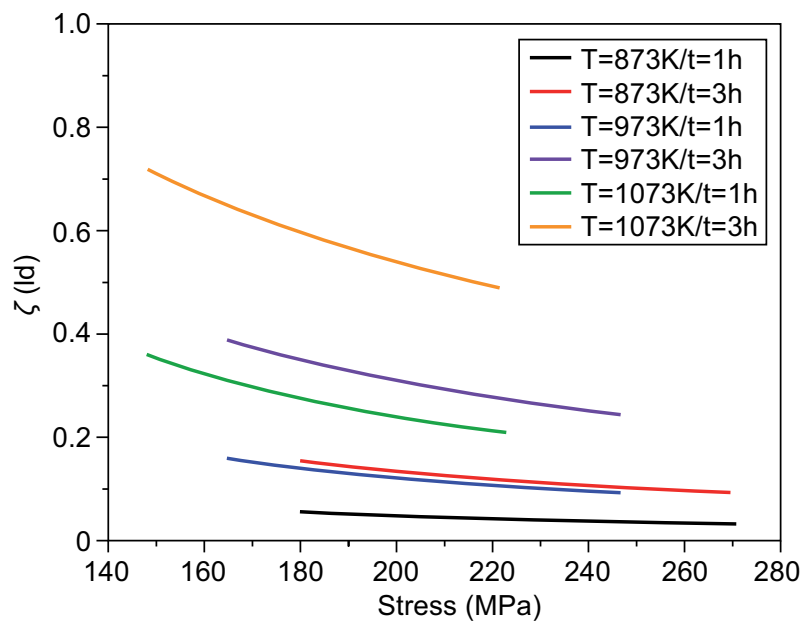

f) $V_{\mathrm{f}}=35 \%$

Figure 2. The matrix cracking density versus the applied stress curves for the different oxidation temperature and time when $V_{\mathrm{f}}=$ $25 \%$ (a), $30 \%$ (c), $35 \%$ (e); the interface oxidation ratio versus the applied stress curves for the different oxidation temperature and time when $V_{\mathrm{f}}=25 \%$ (b), $30 \%$ (d), $35 \%$ (f). 
cracking density increases from $\varphi=0.09 / \mathrm{mm}$ at $\sigma_{\mathrm{cr}}=$ $=96.3 \mathrm{MPa}$ to $\varphi=5.0 / \mathrm{mm}$ at $\sigma_{\text {sat }}=144 \mathrm{MPa}$, and the interface oxidation ratio decreases from $\zeta / l_{\mathrm{d}}=72.8 \%$ to $\zeta / l_{\mathrm{d}}=48.9 \%$.

When $V_{\mathrm{f}}=30 \%$ at $T=873 \mathrm{~K}$ and $t=1 \mathrm{~h}$, the matrix multi-cracking density increases from $\varphi=0.47 / \mathrm{mm}$ at $\sigma_{\text {cr }}=146 \mathrm{MPa}$ to $\varphi=10.36 / \mathrm{mm}$ at $\sigma_{\text {sat }}=167 \mathrm{MPa}$, and the fibre/matrix interface oxidation ratio decreases from $\zeta / l_{\mathrm{d}}=5.6 \%$ to $\zeta / l_{\mathrm{d}}=3.2 \%$; and at $t=3 \mathrm{~h}$, the matrix multi-cracking density increases from $\varphi=0.35 / \mathrm{mm}$ at $\sigma_{\text {cr }}=146 \mathrm{MPa}$ to $\varphi=3.4 / \mathrm{mm}$ at $\sigma_{\text {sat }}=170 \mathrm{MPa}$, and the interface oxidation ratio decreases from $\zeta / l_{\mathrm{d}}=15.6 \%$ to $\zeta / l_{\mathrm{d}}=9.3 \%$. At $T=973 \mathrm{~K}$ and $t=1 \mathrm{~h}$, the matrix multi-cracking density increases from $\varphi=0.21 / \mathrm{mm}$ at $\sigma_{\text {cr }}=134 \mathrm{MPa}$ to $\varphi=8.46 / \mathrm{mm}$ at $\sigma_{\text {sat }}=178 \mathrm{MPa}$, and the interface oxidation ratio decreases from $\zeta / l_{\mathrm{d}}=15.9 \%$ to $\zeta / l_{\mathrm{d}}=9.1 \%$; and at $t=3 \mathrm{~h}$, the matrix multi-cracking density increases from $\varphi=0.15 / \mathrm{mm}$ at $\sigma_{\mathrm{cr}}=134 \mathrm{MPa}$ to $\varphi=6.9 / \mathrm{mm}$ at $\sigma_{\text {sat }}=186 \mathrm{MPa}$, and the interface oxidation ratio decreases from $\zeta / l_{\mathrm{d}}=38.9 \%$ to $\zeta / l_{\mathrm{d}}=24.3 \%$. At $T=1073 \mathrm{~K}$ and $t=1 \mathrm{~h}$, the matrix multi-cracking density increases from $\varphi=0.14 / \mathrm{mm}$ at $\sigma_{\mathrm{cr}}=122 \mathrm{MPa}$ to $\varphi=6.7 / \mathrm{mm}$ at $\sigma_{\text {sat }}=183 \mathrm{MPa}$, and the interface oxidation ratio decreases from $\zeta / l_{\mathrm{d}}=35.7 \%$ to $\zeta / l_{\mathrm{d}}=20.7 \%$; and at $t=3 \mathrm{~h}$, the matrix multi-cracking density increases from $\varphi=0.09 / \mathrm{mm}$ at $\sigma_{\mathrm{cr}}=122 \mathrm{MPa}$ to $\varphi=4.8 / \mathrm{mm}$ at $\sigma_{\text {sat }}=183 \mathrm{MPa}$, and the interface oxidation ratio decreases from $\zeta / l_{\mathrm{d}}=71.5 \%$ to $\zeta / l_{\mathrm{d}}=48.2 \%$.

When $V_{\mathrm{f}}=35 \%$ at $T=873 \mathrm{~K}$ and $t=1 \mathrm{~h}$, the matrix multi-cracking density increases from $\varphi=0.35 / \mathrm{mm}$ at $\sigma_{\text {cr }}=180 \mathrm{MPa}$ to $\varphi=9.75 / \mathrm{mm}$ at $\sigma_{\text {sat }}=215 \mathrm{MPa}$, and the interface oxidation ratio decreases from $\zeta / l_{\mathrm{d}}=5.5 \%$ to $\zeta / l_{\mathrm{d}}=3.2 \%$; and at $t=3 \mathrm{~h}$, the matrix multi-cracking density increases from $\varphi=0.28 / \mathrm{mm}$ at $\sigma_{\text {cr }}=180 \mathrm{MPa}$ to $\varphi=8.9 / \mathrm{mm}$ at $\sigma_{\text {sat }}=219 \mathrm{MPa}$, and the interface oxidation ratio decreases from $\zeta / l_{\mathrm{d}}=15.4 \%$ to $9.2 \%$. At $T=973 \mathrm{~K}$ and $t=1 \mathrm{~h}$, the matrix multi-cracking density increases from $\varphi=0.2 / \mathrm{mm}$ at $\sigma_{\mathrm{cr}}=165 \mathrm{MPa}$ to $\varphi=8.2 / \mathrm{mm}$ at $\sigma_{\text {sat }}=$ $=223 \mathrm{MPa}$, and the interface oxidation ratio decreases from $\zeta / l_{\mathrm{d}}=15.9 \%$ to $\zeta / l_{\mathrm{d}}=9.2 \%$; and at $t=3 \mathrm{~h}$, the matrix multi-cracking density increases from $\varphi=0.15 / \mathrm{mm}$ at $\sigma_{\text {cr }}=165 \mathrm{MPa}$ to $\varphi=6.7 / \mathrm{mm}$ at $\sigma_{\text {sat }}=234 \mathrm{MPa}$, and the interface oxidation ratio decreases from $\zeta / l_{\mathrm{d}}=38.8 \%$ to $\zeta / l_{\mathrm{d}}=24.3 \%$. At $T=1073 \mathrm{~K}$ and $t=1 \mathrm{~h}$, the matrix multi-cracking density increases from $\varphi=0.14 / \mathrm{mm}$ at $\sigma_{\text {cr }}=148 \mathrm{MPa}$ to $\varphi=6.6 / \mathrm{mm}$ at $\sigma_{\text {sat }}=222 \mathrm{MPa}$, and the interface oxidation ratio decreases from $\zeta / l_{\mathrm{d}}=36 \%$ to $\zeta / l_{\mathrm{d}}=21 \%$; and at $t=3 \mathrm{~h}$, the matrix multi-cracking density increases from $\varphi=0.09 / \mathrm{mm}$ at $\sigma_{\mathrm{cr}}=148 \mathrm{MPa}$ to $\varphi=4.8 / \mathrm{mm}$ at $\sigma_{\text {sat }}=222 \mathrm{MPa}$, and the interface oxidation ratio decreases from $\zeta / l_{\mathrm{d}}=71.9 \%$ to $48.7 \%$.

\section{Effect of the fibre/matrix interface shear stress}

The effect of interface shear stress (i.e., $\tau_{0}=15$, 20 and $25 \mathrm{MPa}$ ) on the time-dependent matrix multicracking and the fibre/matrix interface oxidation ratio of the $\mathrm{SiC} / \mathrm{SiC}$ composite at $T=873 \mathrm{~K}, 973 \mathrm{~K}$ and $1073 \mathrm{~K}$ for $t=1 \mathrm{~h}$ and $3 \mathrm{~h}$ are shown in Figure 3.

When $\tau_{0}=15 \mathrm{MPa}$ at $T=873 \mathrm{~K}$ and $t=1 \mathrm{~h}$, the matrix multi-cracking density increases from $\varphi=0.34 / \mathrm{mm}$ at $\sigma_{\text {cr }}=191 \mathrm{MPa}$ to $\varphi=10.33 / \mathrm{mm}$ at $\sigma_{\text {sat }}=234 \mathrm{MPa}$, and the interface oxidation ratio decreases from $\zeta / l_{\mathrm{d}}=6 \%$ to $\zeta / l_{\mathrm{d}}=3.5 \%$; and at $t=3 \mathrm{~h}$, the matrix multi-cracking density increases from $\varphi=0.27 / \mathrm{mm}$ at $\sigma_{\mathrm{cr}}=191 \mathrm{MPa}$ to $\varphi=9.3 / \mathrm{mm}$ at $\sigma_{\text {sat }}=240 \mathrm{MPa}$, and the interface oxidation ratio decreases from $\zeta / l_{\mathrm{d}}=16.6 \%$ to $\zeta / l_{\mathrm{d}}=10.2 \%$. At $T=973 \mathrm{~K}$ and $t=1 \mathrm{~h}$, the matrix multi-cracking density increases from $\varphi=0.21 / \mathrm{mm}$ at $\sigma_{\mathrm{cr}}=176 \mathrm{MPa}$ to $\varphi=$ $=8.7 / \mathrm{mm}$ at $\sigma_{\text {sat }}=245 \mathrm{MPa}$, and the interface oxidation ratio decreases from $\zeta / l_{\mathrm{d}}=17.1 \%$ to $\zeta / l_{\mathrm{d}}=10.1 \%$; and at $t=3 \mathrm{~h}$, the matrix multi-cracking density increases from $\varphi=0.15 / \mathrm{mm}$ at $\sigma_{\mathrm{cr}}=176 \mathrm{MPa}$ to $\varphi=7 / \mathrm{mm}$ at $\sigma_{\text {sat }}=$ $=258 \mathrm{MPa}$, and the interface oxidation ratio decreases from $\zeta / l_{\mathrm{d}}=40.6 \%$ to $\zeta / l_{\mathrm{d}}=26.3 \%$. At $T=1073 \mathrm{~K}$ and $t=1 \mathrm{~h}$, the matrix multi-cracking density increases from $\varphi=0.15 / \mathrm{mm}$ at $\sigma_{\text {cr }}=159 \mathrm{MPa}$ to $\varphi=7 / \mathrm{mm}$ at $\sigma_{\text {sat }}=$ $=239 \mathrm{MPa}$, and the interface oxidation ratio decreases from $\zeta / l_{\mathrm{d}}=37.5 \%$ to $\zeta / l_{\mathrm{d}}=22.8 \%$; and at $t=3 \mathrm{~h}$, the matrix multi-cracking density increases from $\varphi=0.09 / \mathrm{mm}$ at $\sigma_{\mathrm{cr}}=159 \mathrm{MPa}$ to $\varphi=4.8 / \mathrm{mm}$ at $\sigma_{\text {sat }}=239 \mathrm{MPa}$, and the interface oxidation ratio decreases from $\zeta / l_{\mathrm{d}}=71.7 \%$ to $\zeta / l_{\mathrm{d}}=50.9 \%$.

When $\tau_{0}=20 \mathrm{MPa}$ at $T=873 \mathrm{~K}$ and $t=1 \mathrm{~h}$, the matrix multi-cracking density increases from $\varphi=0.34 / \mathrm{mm}$ at $\sigma_{\text {cr }}=201 \mathrm{MPa}$ to $\varphi=10.89 / \mathrm{mm}$ at $\sigma_{\text {sat }}=251 \mathrm{MPa}$, and the interface oxidation ratio decreases from $\zeta / l_{\mathrm{d}}=6.5 \%$ to $\zeta / l_{\mathrm{d}}=3.9 \%$; and at $t=3 \mathrm{~h}$, the matrix multi-cracking density increases from $\varphi=0.27 / \mathrm{mm}$ at $\sigma_{\mathrm{cr}}=201 \mathrm{MPa}$ to $\varphi=9.7 / \mathrm{mm}$ at $\sigma_{\text {sat }}=260 \mathrm{MPa}$, and the interface oxidation ratio decreases from $\zeta / l_{\mathrm{d}}=17.7 \%$ to $\zeta / l_{\mathrm{d}}=11 \%$. At $T=973 \mathrm{~K}$ and $t=1 \mathrm{~h}$, the matrix multi-cracking density increases from $\varphi=0.22 / \mathrm{mm}$ at $\sigma_{\mathrm{cr}}=186 \mathrm{MPa}$ to $\varphi=9.26 / \mathrm{mm}$ at $\sigma_{\text {sat }}=265 \mathrm{MPa}$, and the interface oxidation ratio decreases from $\zeta / l_{\mathrm{d}}=18.2 \%$ to $\zeta / l_{\mathrm{d}}=11 \%$; and at $t=3 \mathrm{~h}$, the matrix multi-cracking density increases from $\varphi=0.15 / \mathrm{mm}$ at $\sigma_{\mathrm{cr}}=186 \mathrm{MPa}$ to $\varphi=7.3 / \mathrm{mm}$ at $\sigma_{\text {sat }}=280 \mathrm{MPa}$, and the interface oxidation ratio decreases from $\zeta / l_{\mathrm{d}}=42.3 \%$ to $\zeta / l_{\mathrm{d}}=28.1 \%$. At $T=1073 \mathrm{~K}$ and $t=1 \mathrm{~h}$, the matrix multi-cracking density increases from $\varphi=0.15 / \mathrm{mm}$ at $\sigma_{\mathrm{cr}}=169 \mathrm{MPa}$ to $\varphi=7.4 / \mathrm{mm}$ at $\sigma_{\text {sat }}=254 \mathrm{MPa}$, and the interface oxidation ratio decreases from $\zeta / l_{\mathrm{d}}=39 \%$ to $\zeta / l_{\mathrm{d}}=24.5 \%$; and at $t=3 \mathrm{~h}$, the matrix multi-cracking density increases from $\varphi=0.09 / \mathrm{mm}$ at $\sigma_{\text {cr }}=169 \mathrm{MPa}$ to $\varphi=4.9 / \mathrm{mm}$ at $\sigma_{\text {sat }}=254 \mathrm{MPa}$, and the interface oxidation ratio decreases from $\zeta / l_{\mathrm{d}}=72.1 \%$ to $\zeta / l_{\mathrm{d}}=52.9 \%$.

When $\tau_{0}=25 \mathrm{MPa}$ at $T=873 \mathrm{~K}$ and $t=1 \mathrm{~h}$, the matrix multi-cracking density increases from $\varphi=0.35 / \mathrm{mm}$ at $\sigma_{\text {cr }}=211 \mathrm{MPa}$ to $\varphi=11.4 / \mathrm{mm}$ at $\sigma_{\text {sat }}=270 \mathrm{MPa}$, and the interface oxidation ratio decreases from $\zeta / l_{\mathrm{d}}=7 \%$ to $\zeta / l_{\mathrm{d}}=4.2 \%$; and at $t=3 \mathrm{~h}$, the matrix multi-cracking density increases from $\varphi=0.28 / \mathrm{mm}$ at $\sigma_{\mathrm{cr}}=211 \mathrm{MPa}$ to $\varphi=10.2 / \mathrm{mm}$ at $\sigma_{\text {sat }}=277 \mathrm{MPa}$, and the interface oxidation ratio decreases from $\zeta / l_{\mathrm{d}}=18.8 \%$ to $\zeta / l_{\mathrm{d}}=11.8 \%$. 
At $T=973 \mathrm{~K}$ and $t=1 \mathrm{~h}$, the matrix multi-cracking density increases from $\varphi=0.23 / \mathrm{mm}$ at $\sigma_{\mathrm{cr}}=195 \mathrm{MPa}$ to $\varphi=9.7 / \mathrm{mm}$ at $\sigma_{\text {sat }}=282 \mathrm{MPa}$, and the interface oxidation ratio decreases from $\zeta / l_{\mathrm{d}}=19.3 \%$ to $\zeta / l_{\mathrm{d}}=11.8 \%$;

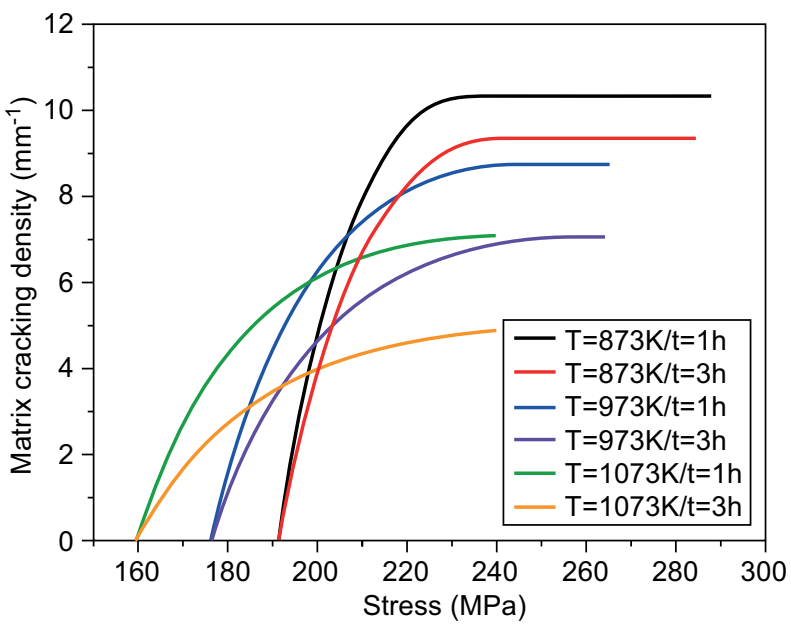

a) $\tau_{0}=15 \mathrm{MPa}$

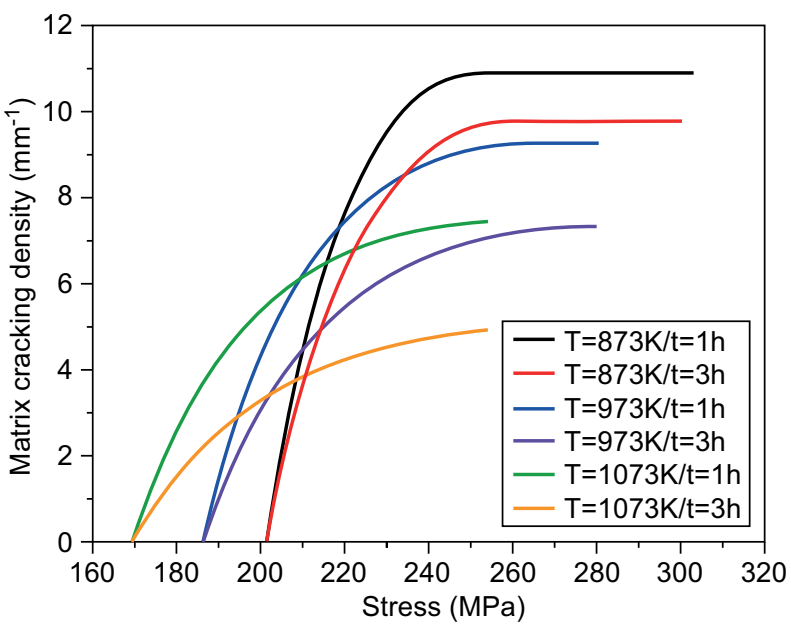

c) $\tau_{0}=20 \mathrm{MPa}$

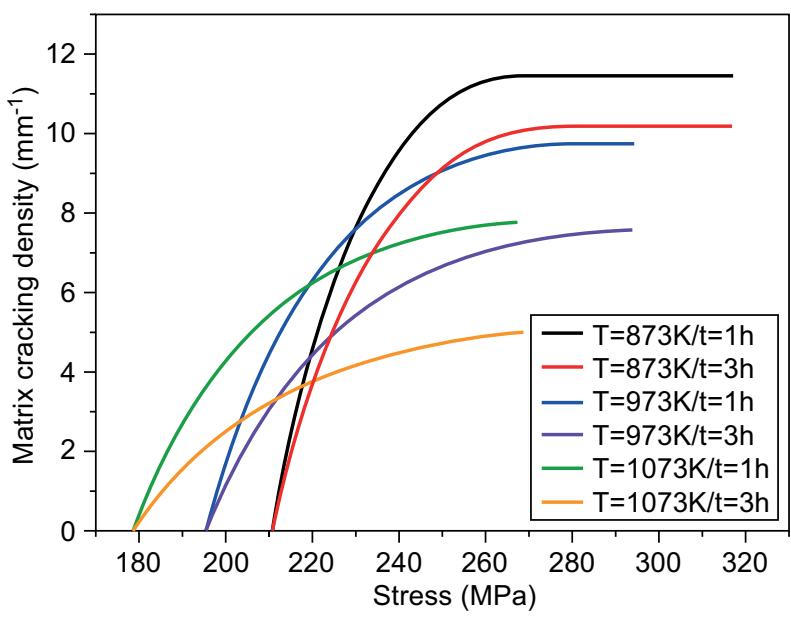

e) $\tau_{0}=25 \mathrm{MPa}$ and at $t=3 \mathrm{~h}$, the matrix multi-cracking density increases from $\varphi=0.15 / \mathrm{mm}$ at $\sigma_{\mathrm{cr}}=195 \mathrm{MPa}$ to $\varphi=7.5 / \mathrm{mm}$ at $\sigma_{\text {sat }}=293 \mathrm{MPa}$, and the interface oxidation ratio decreases from $\zeta / l_{\mathrm{d}}=43.8 \%$ to $\zeta / l_{\mathrm{d}}=29.7 \%$. At $T=1073 \mathrm{~K}$

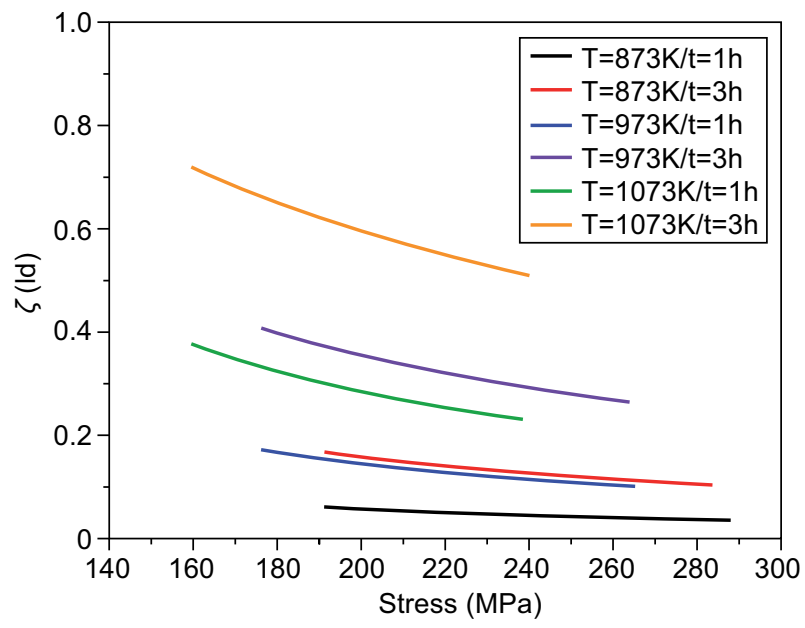

b) $\tau_{0}=15 \mathrm{MPa}$

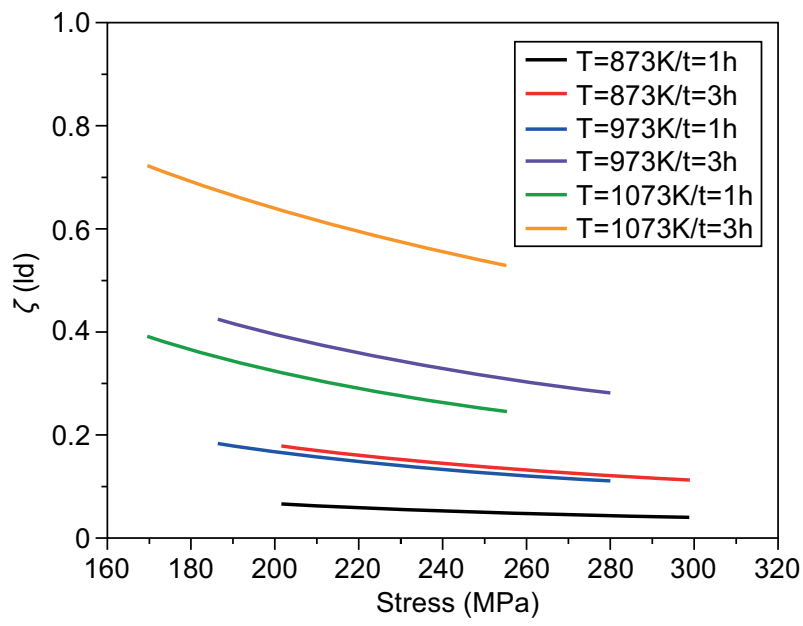

d) $\tau_{0}=20 \mathrm{MPa}$

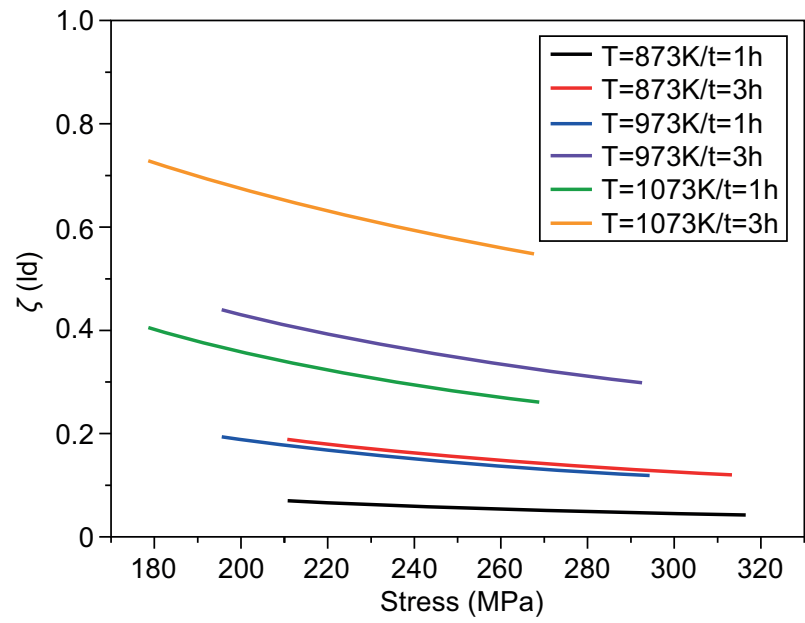

f) $\tau_{0}=25 \mathrm{MPa}$

Figure 3. The matrix cracking density versus the applied stress curves for the different oxidation temperature and time when $\tau_{0}=15 \mathrm{MPa}(\mathrm{a}), 20 \mathrm{MPa}(\mathrm{c}), 25 \mathrm{MPa}$ (e); the interface oxidation ratio versus the applied stress curves for the different oxidation temperature and time when $\tau_{0}=15 \mathrm{MPa}(\mathrm{b}), 20 \mathrm{MPa}(\mathrm{d}), 25 \mathrm{MPa}(\mathrm{f})$. 
and $t=1 \mathrm{~h}$, the matrix multi-cracking density increases from $\varphi=0.16 / \mathrm{mm}$ at $\sigma_{\mathrm{cr}}=178 \mathrm{MPa}$ to $\varphi=7.7 / \mathrm{mm}$ at $\sigma_{\text {sat }}=268 \mathrm{MPa}$, and the interface oxidation ratio decreases from $\zeta / l_{\mathrm{d}}=40.4 \%$ to $\zeta / l_{\mathrm{d}}=26.1 \%$; and at $t=3 \mathrm{~h}$, the ma-

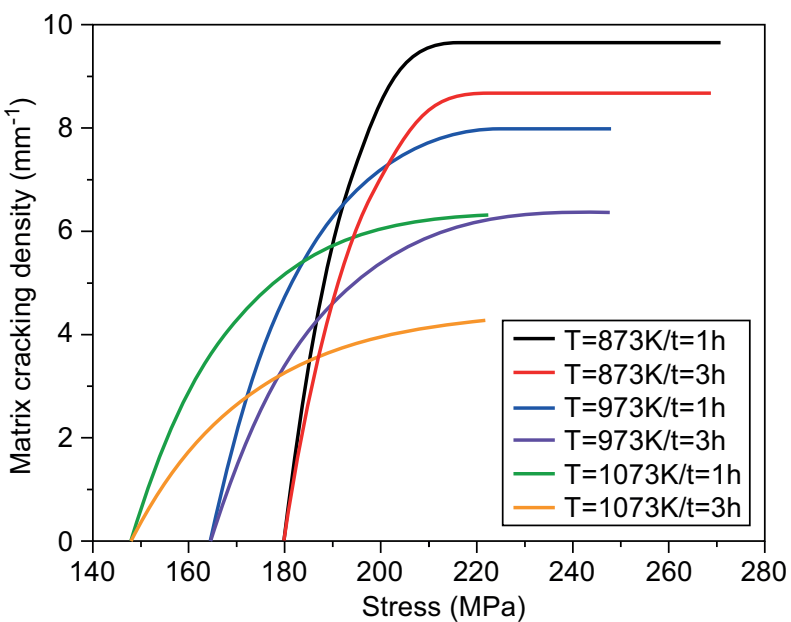

a) $\tau_{\mathrm{f}}=1 \mathrm{MPa}$

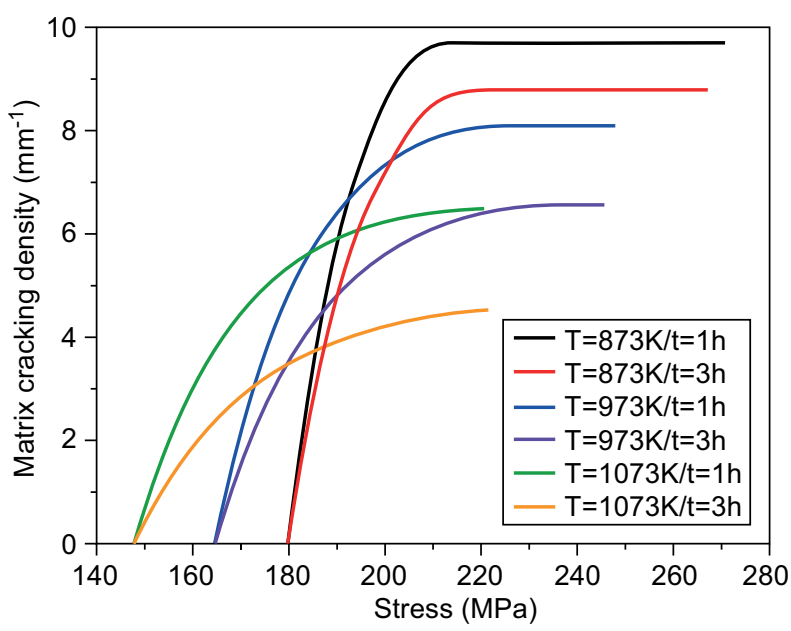

c) $\tau_{\mathrm{f}}=3 \mathrm{MPa}$

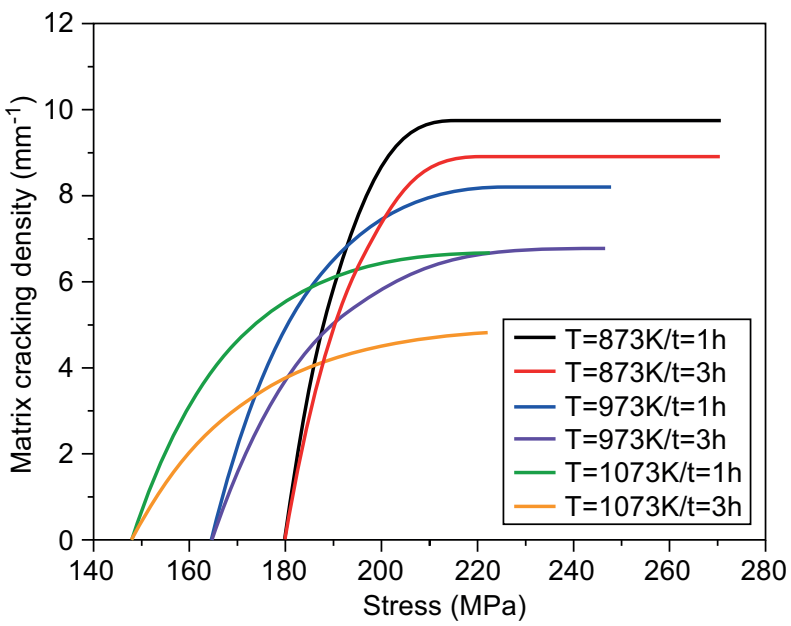

e) $\tau_{\mathrm{f}}=5 \mathrm{MPa}$ trix multi-cracking density increases from $\varphi=0.09 / \mathrm{mm}$ at $\sigma_{\text {cr }}=178 \mathrm{MPa}$ to $\varphi=5 / \mathrm{mm}$ at $\sigma_{\text {sat }}=268 \mathrm{MPa}$, and the interface oxidation ratio decreases from $\zeta / l_{\mathrm{d}}=72.6 \%$ to $\zeta / l_{\mathrm{d}}=54.6 \%$.

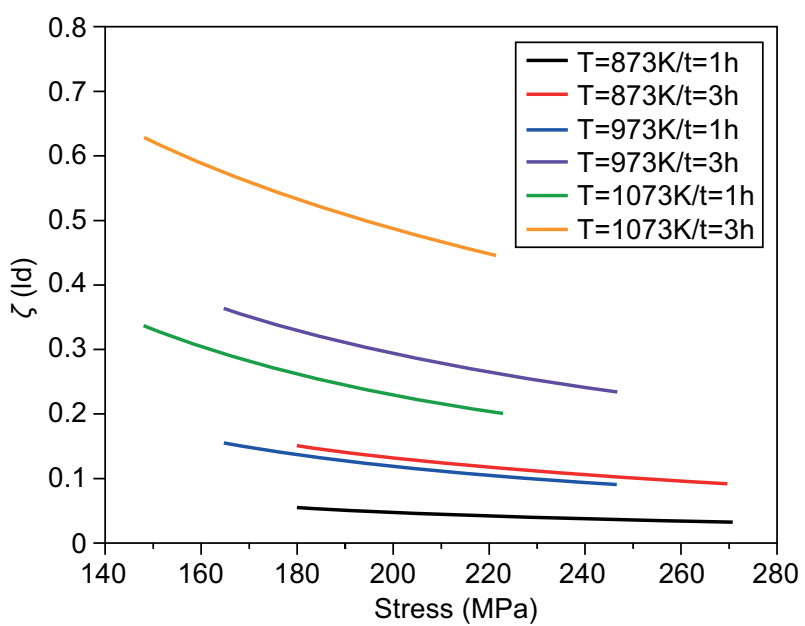

b) $\tau_{\mathrm{f}}=1 \mathrm{MPa}$

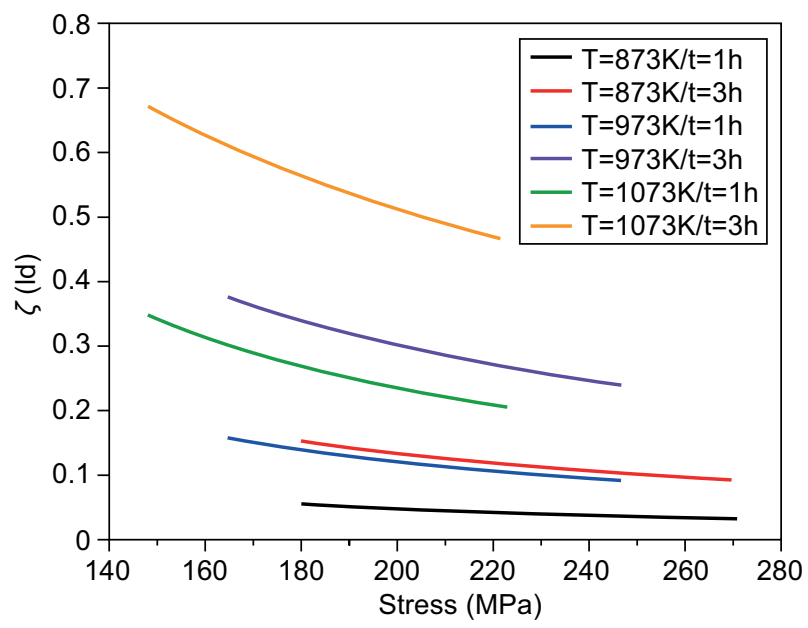

d) $\tau_{\mathrm{f}}=3 \mathrm{MPa}$

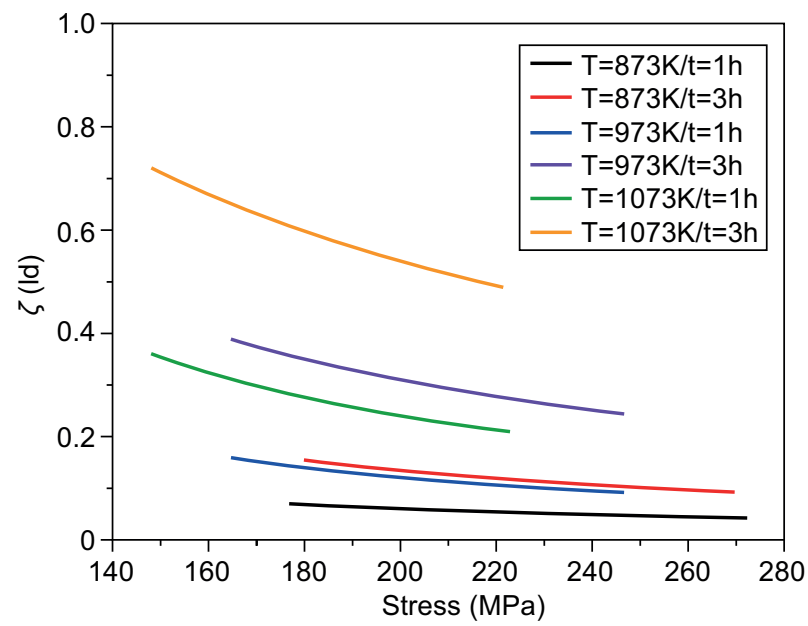

f) $\tau_{\mathrm{f}}=5 \mathrm{MPa}$

Figure 4. The matrix cracking density versus the applied stress curves for the different oxidation temperature and time when $\tau_{\mathrm{f}}=1 \mathrm{MPa}(\mathrm{a}), 3 \mathrm{MPa}(\mathrm{c}), 5 \mathrm{MPa}(\mathrm{e})$; the interface oxidation ratio versus the applied stress curves for the different oxidation temperature and time when $\tau_{\mathrm{f}}=1 \mathrm{MPa}(\mathrm{b}), 3 \mathrm{MPa}(\mathrm{d}), 5 \mathrm{MPa}(\mathrm{f})$. 
The effect of interface shear stress (i.e., $\tau_{\mathrm{f}}=1,3$ and $5 \mathrm{MPa}$ ) on the time-dependent matrix multi-cracking and the fibre/matrix interface oxidation of the $\mathrm{SiC} / \mathrm{SiC}$ composite at $T=873 \mathrm{~K}, 973 \mathrm{~K}$ and $1073 \mathrm{~K}$ for $t=1 \mathrm{~h}$ and $3 \mathrm{~h}$ are shown in Figure 4.

When $\tau_{\mathrm{f}}=1 \mathrm{MPa}$ at $T=873 \mathrm{~K}$ and $t=1 \mathrm{~h}$, the matrix multi-cracking density increases from $\varphi=0.34 / \mathrm{mm}$ at $\sigma_{\text {cr }}=180 \mathrm{MPa}$ to $\varphi=9.6 / \mathrm{mm}$ at $\sigma_{\text {sat }}=214 \mathrm{MPa}$, and the interface oxidation ratio decreases from $\zeta / l_{\mathrm{d}}=5.5 \%$ to $\zeta / l_{\mathrm{d}}=3.2 \%$; and at $t=3 \mathrm{~h}$, the matrix multi-cracking density increases from $\varphi=0.27 / \mathrm{mm}$ at $\sigma_{\mathrm{cr}}=180 \mathrm{MPa}$ to $\varphi=8.6 / \mathrm{mm}$ at $\sigma_{\text {sat }}=220 \mathrm{MPa}$, and the interface oxidation ratio decreases from $\zeta / l_{\mathrm{d}}=15 \%$ to $\zeta / l_{\mathrm{d}}=9.1 \%$. At $T=973 \mathrm{~K}$ and $t=1 \mathrm{~h}$, the matrix multi-cracking density increases from $\varphi=0.19 / \mathrm{mm}$ at $\sigma_{\mathrm{cr}}=165 \mathrm{MPa}$ to $\varphi=$ $=7.9 / \mathrm{mm}$ at $\sigma_{\text {sat }}=225 \mathrm{MPa}$, and the interface oxidation ratio decreases from $\zeta / l_{\mathrm{d}}=15.4 \%$ to $\zeta / l_{\mathrm{d}}=9 \%$; and at $t=3 \mathrm{~h}$, the matrix multi-cracking density increases from $\varphi=0.13 / \mathrm{mm}$ at $\sigma_{\text {cr }}=165 \mathrm{MPa}$ to $\varphi=6.3 / \mathrm{mm}$ at $\sigma_{\text {sat }}=$ $=237 \mathrm{MPa}$, and the interface oxidation ratio decreases from $\zeta / l_{\mathrm{d}}=36.2 \%$ to $\zeta / l_{\mathrm{d}}=23.3 \%$. At $T=1073 \mathrm{~K}$ and $t=1 \mathrm{~h}$, the matrix multi-cracking density increases from $\varphi=0.13 / \mathrm{mm}$ at $\sigma_{\text {cr }}=148 \mathrm{MPa}$ to $\varphi=6.3 / \mathrm{mm}$ at $\sigma_{\text {sat }}=$ $=222 \mathrm{MPa}$, and the interface oxidation ratio decreases from $\zeta / l_{\mathrm{d}}=33.5 \%$ to $\zeta / l_{\mathrm{d}}=20 \%$; and at $t=3 \mathrm{~h}$, the matrix multi-cracking density increases from $\varphi=0.07 / \mathrm{mm}$ at $\sigma_{\text {cr }}=148 \mathrm{MPa}$ to $\varphi=4.2 / \mathrm{mm}$ at $\sigma_{\text {sat }}=222 \mathrm{MPa}$, and the interface oxidation ratio decreases from $\zeta / l_{\mathrm{d}}=62.7 \%$ to $\zeta / l_{\mathrm{d}}=44.3 \%$.

When $\tau_{\mathrm{f}}=3 \mathrm{MPa}$ at $T=873 \mathrm{~K}$ and $t=1 \mathrm{~h}$, the matrix multi-cracking density increases from $\varphi=0.35 / \mathrm{mm}$ at $\sigma_{\mathrm{cr}}=180 \mathrm{MPa}$ to $\varphi=9.7 / \mathrm{mm}$ at $\sigma_{\text {sat }}=214 \mathrm{MPa}$, and the interface oxidation ratio decreases from $\zeta / l_{\mathrm{d}}=5.5 \%$ to $\zeta / l_{\mathrm{d}}=3.2 \%$; and at $t=3 \mathrm{~h}$, the matrix multi-cracking density increases from $\varphi=0.28 / \mathrm{mm}$ at $\sigma_{\mathrm{cr}}=180 \mathrm{MPa}$ to $\varphi=8.7 / \mathrm{mm}$ at $\sigma_{\text {sat }}=220 \mathrm{MPa}$, and the interface oxidation ratio decreases from $\zeta / l_{\mathrm{d}}=15.2 \%$ to $\zeta / l_{\mathrm{d}}=9.2 \%$. At $T=973 \mathrm{~K}$ and $t=1 \mathrm{~h}$, the matrix multi-cracking density increases from $\varphi=0.2 / \mathrm{mm}$ at $\sigma_{\mathrm{cr}}=165 \mathrm{MPa}$ to $\varphi=$ $=8.0 / \mathrm{mm}$ at $\sigma_{\text {sat }}=224 \mathrm{MPa}$, and the interface oxidation ratio decreases from $\zeta / l_{\mathrm{d}}=15.6 \%$ to $\zeta / l_{\mathrm{d}}=9.1 \%$; and at $t=3 \mathrm{~h}$, the matrix multi-cracking density increases from $\varphi=0.14 / \mathrm{mm}$ at $\sigma_{\mathrm{cr}}=165 \mathrm{MPa}$ to $\varphi=6.5 / \mathrm{mm}$ at $\sigma_{\text {sat }}=236 \mathrm{MPa}$, and the interface oxidation ratio decreases from $\zeta / l_{\mathrm{d}}=37.5 \%$ to $\zeta / l_{\mathrm{d}}=23.8 \%$. At $T=1073 \mathrm{~K}$ and $t=1 \mathrm{~h}$, the matrix multi-cracking density increases from $\varphi=0.14 / \mathrm{mm}$ at $\sigma_{\mathrm{cr}}=148 \mathrm{MPa}$ to $\varphi=6.4 / \mathrm{mm}$ at $\sigma_{\text {sat }}=222 \mathrm{MPa}$, and the interface oxidation ratio decreases from $\zeta / l_{\mathrm{d}}=34.7 \%$ to $\zeta / l_{\mathrm{d}}=20.5 \%$; and at $t=3 \mathrm{~h}$, the matrix multi-cracking density increases from $\varphi=0.08 / \mathrm{mm}$ at $\sigma_{\text {cr }}=148 \mathrm{MPa}$ to $\varphi=4.5 / \mathrm{mm}$ at $\sigma_{\text {sat }}=222 \mathrm{MPa}$, and the interface oxidation ratio decreases from $\zeta / l_{\mathrm{d}}=67 \%$ to $\zeta / l_{\mathrm{d}}=46.4 \%$.

When $\tau_{\mathrm{f}}=5 \mathrm{MPa}$ at $T=873 \mathrm{~K}$ and $t=1 \mathrm{~h}$, the matrix multi-cracking density increases from $\varphi=0.35 / \mathrm{mm}$ at $\sigma_{\mathrm{cr}}=180 \mathrm{MPa}$ to $\varphi=9.7 / \mathrm{mm}$ at $\sigma_{\text {sat }}=214 \mathrm{MPa}$, and the interface oxidation ratio decreases from $\zeta / l_{\mathrm{d}}=5.5 \%$ to $\zeta / l_{\mathrm{d}}=3.2 \%$; and at $t=3 \mathrm{~h}$, the matrix multi-cracking density increases from $\varphi=0.29 / \mathrm{mm}$ at $\sigma_{\text {cr }}=180 \mathrm{MPa}$ to $\varphi=8.9 / \mathrm{mm}$ at $\sigma_{\text {sat }}=220 \mathrm{MPa}$, and the interface oxidation ratio decreases from $\zeta / l_{\mathrm{d}}=15.4 \%$ to $\zeta / l_{\mathrm{d}}=9.3 \%$. At $T=973 \mathrm{~K}$ and $t=1 \mathrm{~h}$, the matrix multi-cracking density increases from $\varphi=0.2 / \mathrm{mm}$ at $\sigma_{\text {cr }}=165 \mathrm{MPa}$ to $\varphi=8.2 / \mathrm{mm}$ at $\sigma_{\text {sat }}=224 \mathrm{MPa}$, and the interface oxidation ratio decreases from $\zeta / l_{\mathrm{d}}=15.9 \%$ to $\zeta / l_{\mathrm{d}}=9.2 \%$; and at $t=3 \mathrm{~h}$, the matrix multi-cracking density increases from $\varphi=0.15 / \mathrm{mm}$ at $\sigma_{\mathrm{cr}}=165 \mathrm{MPa}$ to $\varphi=6.7 / \mathrm{mm}$ at $\sigma_{\text {sat }}=234 \mathrm{MPa}$, and the interface oxidation ratio decreases from $\zeta / l_{\mathrm{d}}=38.8 \%$ to $\zeta / l_{\mathrm{d}}=24.3 \%$. At $T=1073 \mathrm{~K}$ and $t=1 \mathrm{~h}$, the matrix multi-cracking density increases from $\varphi=0.15 / \mathrm{mm}$ at $\sigma_{\text {cr }}=148 \mathrm{MPa}$ to $\varphi=6.6 / \mathrm{mm}$ at $\sigma_{\text {sat }}=222 \mathrm{MPa}$, and the interface oxidation ratio decreases from $\zeta / l_{\mathrm{d}}=36 \%$ to $\zeta / l_{\mathrm{d}}=21 \%$; and at $t=3 \mathrm{~h}$, the matrix multi-cracking density increases from $\varphi=0.09 / \mathrm{mm}$ at $\sigma_{\mathrm{cr}}=148 \mathrm{MPa}$ to $\varphi=4.8 / \mathrm{mm}$ at $\sigma_{\text {sat }}=222 \mathrm{MPa}$, and the interface oxidation ratio decreases from $\zeta / l_{\mathrm{d}}=72 \%$ to $\zeta / l_{\mathrm{d}}=48.7 \%$.

\section{Effect of the fibre/matrix interface frictional coefficient}

The effect of the fibre/matrix interface frictional coefficient (i.e., $\mu=0.05,0.1$ and 0.15 ) on the timedependent matrix multi-cracking and the fibre/matrix interface oxidation ratio of the $\mathrm{SiC} / \mathrm{SiC}$ composite at $T=873 \mathrm{~K}, 973 \mathrm{~K}$ and $1073 \mathrm{~K}$ for $t=1 \mathrm{~h}$ and $3 \mathrm{~h}$ are shown in Figure 5.

When $\mu=0.05$ at $T=873 \mathrm{~K}$ and $t=1 \mathrm{~h}$, the matrix multi-cracking density increases from $\varphi=1.2 / \mathrm{mm}$ at $\sigma_{\mathrm{cr}}=128 \mathrm{MPa}$ to $\varphi=9.9 / \mathrm{mm}$ at $\sigma_{\text {sat }}=136 \mathrm{MPa}$, and the interface oxidation ratio decreases from $\zeta / l_{\mathrm{d}}=4.9 \%$ to $\zeta / l_{\mathrm{d}}=2.7 \%$; and at $t=3 \mathrm{~h}$, the matrix multi-cracking density increases from $\varphi=0.71 / \mathrm{mm}$ at $\sigma_{\mathrm{cr}}=128 \mathrm{MPa}$ to $\varphi=9.2 / \mathrm{mm}$ at $\sigma_{\text {sat }}=138 \mathrm{MPa}$, and the interface oxidation ratio decreases from $\zeta / l_{\mathrm{d}}=13.8 \%$ to $\zeta / l_{\mathrm{d}}=7.9 \%$. At $T=973 \mathrm{~K}$ and $\mathrm{t}=1 \mathrm{~h}$, the matrix multi-cracking density increases from $\varphi=0.21 / \mathrm{mm}$ at $\sigma_{\mathrm{cr}}=120 \mathrm{MPa}$ to $\varphi=7.9 / \mathrm{mm}$ at $\sigma_{\text {sat }}=151 \mathrm{MPa}$, and the interface oxidation ratio decreases from $\zeta / l_{\mathrm{d}}=14.5 \%$ to $\zeta / l_{\mathrm{d}}=7.9 \%$; and at $t=3 \mathrm{~h}$, the matrix multi-cracking density increases from $\varphi=0.16 / \mathrm{mm}$ at $\sigma_{\mathrm{cr}}=120 \mathrm{MPa}$ to $\varphi=6.7 / \mathrm{mm}$ at $\sigma_{\text {sat }}=156 \mathrm{MPa}$, and the interface oxidation ratio decreases from $\zeta / l_{\mathrm{d}}=37.1 \%$ to $\zeta / l_{\mathrm{d}}=21.7 \%$. At $T=1073 \mathrm{~K}$ and $t=1 \mathrm{~h}$, the matrix multi-cracking density increases from $\varphi=0.14 / \mathrm{mm}$ at $\sigma_{\text {cr }}=110 \mathrm{MPa}$ to $\varphi=6.3 / \mathrm{mm}$ at $\sigma_{\text {sat }}=$ $=162 \mathrm{MPa}$, and the interface oxidation ratio decreases from $\zeta / l_{\mathrm{d}}=34.8 \%$ to $\zeta / l_{\mathrm{d}}=18.8 \%$; and at $t=3 \mathrm{~h}$, the matrix multi-cracking density increases from $\varphi=0.09 / \mathrm{mm}$ at $\sigma_{\text {cr }}=110 \mathrm{MPa}$ to $\varphi=4.8 / \mathrm{mm}$ at $\sigma_{\text {sat }}=166 \mathrm{MPa}$, and the interface oxidation ratio decreases from $\zeta / l_{\mathrm{d}}=73.7 \%$ to $\zeta / l_{\mathrm{d}}=46.1 \%$.

When $\mu=0.1$ at $T=873 \mathrm{~K}$ and $t=1 \mathrm{~h}$, the matrix multi-cracking density increases from $\varphi=0.47 / \mathrm{mm}$ at $\sigma_{\mathrm{cr}}=146 \mathrm{MPa}$ to $\varphi=10.3 / \mathrm{mm}$ at $\sigma_{\text {sat }}=167 \mathrm{MPa}$, and the 
interface oxidation ratio decreases from $\zeta / l_{\mathrm{d}}=5.6 \%$ to $\zeta / l_{\mathrm{d}}=3.2 \%$; and at $t=3 \mathrm{~h}$, the matrix multi-cracking density increases from $\varphi=0.35 / \mathrm{mm}$ at $\sigma_{\mathrm{cr}}=146 \mathrm{MPa}$ to $\varphi=9.4 / \mathrm{mm}$ at $\sigma_{\text {sat }}=170 \mathrm{MPa}$, and the interface oxida-

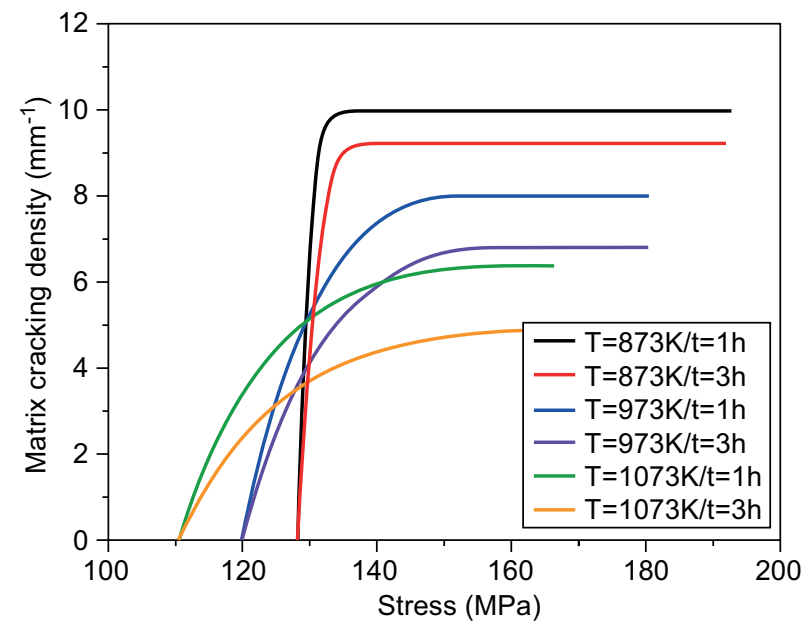

a) $\mu=0.05$

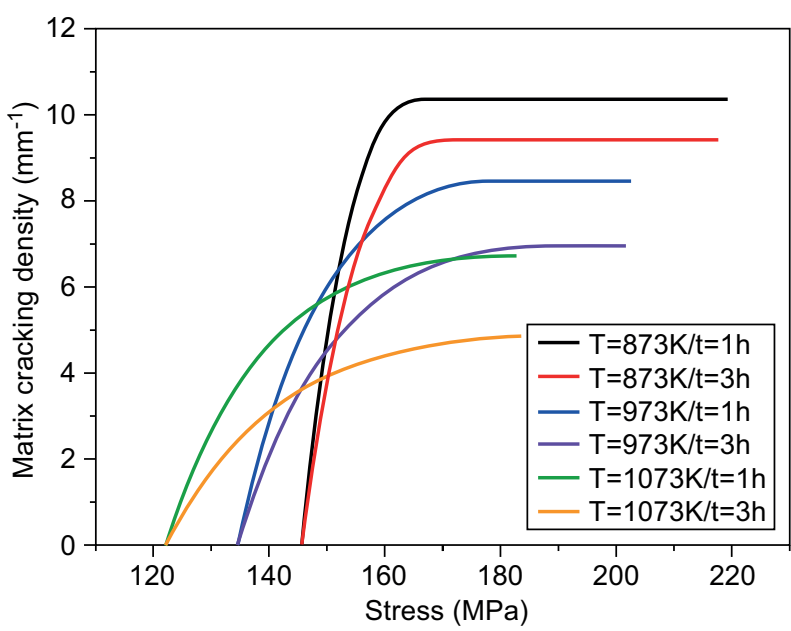

c) $\mu=0.10$

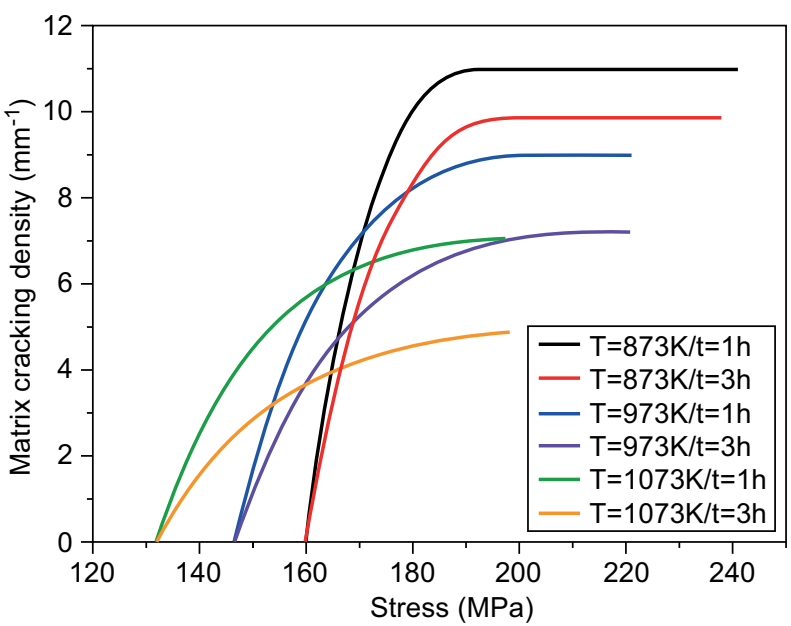

e) $\mu=0.15$ tion ratio decreases from $\zeta / l_{\mathrm{d}}=15.6 \%$ to $\zeta / l_{\mathrm{d}}=9.3 \%$. At $T=973 \mathrm{~K}$ and $t=1 \mathrm{~h}$, the matrix multi-cracking density increases from $\varphi=0.21 / \mathrm{mm}$ at $\sigma_{\mathrm{cr}}=134 \mathrm{MPa}$ to $\varphi=8.4 / \mathrm{mm}$ at $\sigma_{\text {sat }}=178 \mathrm{MPa}$, and the interface oxidation

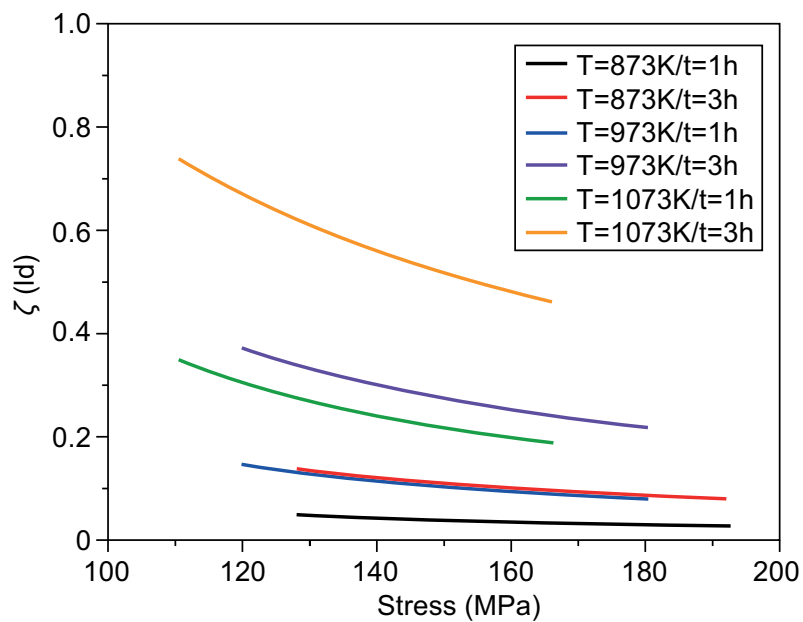

b) $\mu=0.05$

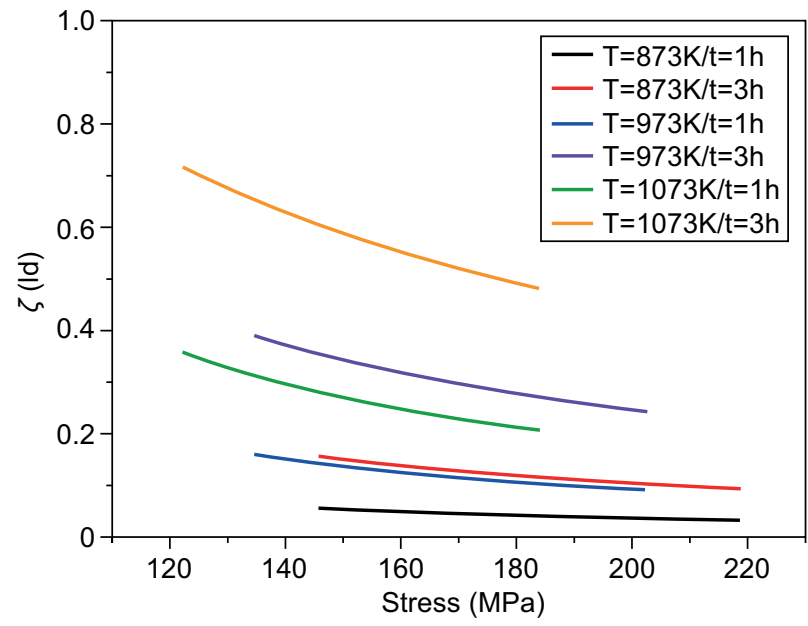

d) $\mu=0.10$

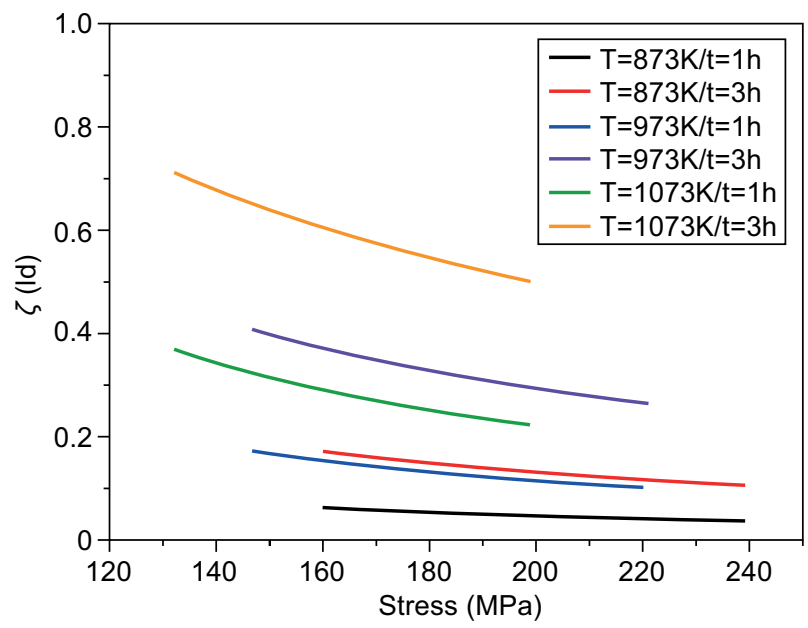

f) $\mu=0.15$

Figure 5. The matrix cracking density versus the applied stress curves for the different oxidation temperature and time when $\mu=0.05$ (a), 0.10 (c), 0.15 (e); the interface oxidation ratio versus the applied stress curves for the different oxidation temperature and time when $\mu=0.05$ (b), 0.10 (d), 0.15 (f). 
ratio decreases from $\zeta / l_{\mathrm{d}}=15.9 \%$ to $\zeta / l_{\mathrm{d}}=9.1 \%$; and at $t=3 \mathrm{~h}$, the matrix multi-cracking density increases from $\varphi=0.15 / \mathrm{mm}$ at $\sigma_{\text {cr }}=134 \mathrm{MPa}$ to $\varphi=6.9 / \mathrm{mm}$ at $\sigma_{\text {sat }}=186 \mathrm{MPa}$, and the interface oxidation ratio decreases from $\zeta / l_{\mathrm{d}}=38.9 \%$ to $\zeta / l_{\mathrm{d}}=24.3 \%$. At $T=1073 \mathrm{~K}$ and $t=1 \mathrm{~h}$, the matrix multi-cracking density increases from $\varphi=0.14 / \mathrm{mm}$ at $\sigma_{\text {cr }}=122 \mathrm{MPa}$ to $\varphi=6.7 / \mathrm{mm}$ at $\sigma_{\text {sat }}=$ $=183 \mathrm{MPa}$, and the interface oxidation ratio decreases from $\zeta / l_{\mathrm{d}}=35.7 \%$ to $\zeta / l_{\mathrm{d}}=20.7 \%$; and at $t=3 \mathrm{~h}$, the matrix multi-cracking density increases from $\varphi=0.09 / \mathrm{mm}$ at $\sigma_{\mathrm{cr}}=122 \mathrm{MPa}$ to $\varphi=4.8 / \mathrm{mm}$ at $\sigma_{\text {sat }}=183 \mathrm{MPa}$, and the interface oxidation ratio decreases from $\zeta / l_{\mathrm{d}}=71.5 \%$ to $\zeta / l_{\mathrm{d}}=48.2 \%$.

When $\mu=0.15$ at $T=873 \mathrm{~K}$ and $t=1 \mathrm{~h}$, the matrix multi-cracking density increases from $\varphi=0.4 / \mathrm{mm}$ at $\sigma_{\text {cr }}=160 \mathrm{MPa}$ to $\varphi=10.9 / \mathrm{mm}$ at $\sigma_{\text {sat }}=193 \mathrm{MPa}$, and the interface oxidation ratio decreases from $\zeta / l_{\mathrm{d}}=6.3 \%$ to $\zeta / l_{\mathrm{d}}=3.7 \%$; and at $t=3 \mathrm{~h}$, the matrix multi-cracking density increases from $\varphi=0.31 / \mathrm{mm}$ at $\sigma_{\text {cr }}=160 \mathrm{MPa}$ to $\varphi=9.8 / \mathrm{mm}$ at $\sigma_{\text {sat }}=198 \mathrm{MPa}$, and the interface oxidation ratio decreases from $\zeta / l_{\mathrm{d}}=17.1 \%$ to $\zeta / l_{\mathrm{d}}=10.5 \%$. At $T=973 \mathrm{~K}$ and $t=1 \mathrm{~h}$, the matrix multi-cracking density increases from $\varphi=0.22 / \mathrm{mm}$ at $\sigma_{\mathrm{cr}}=147 \mathrm{MPa}$ to $\varphi=8.9 / \mathrm{mm}$ at $\sigma_{\text {sat }}=201 \mathrm{MPa}$, and the interface oxidation ratio decreases from $\zeta / l_{\mathrm{d}}=17.2 \%$ to $\zeta / l_{\mathrm{d}}=10.2 \%$; and at $t=3 \mathrm{~h}$, the matrix multi-cracking density increases from $\varphi=0.15 / \mathrm{mm}$ at $\sigma_{\mathrm{cr}}=147 \mathrm{MPa}$ to $\varphi=7.2 / \mathrm{mm}$ at $\sigma_{\text {sat }}=212 \mathrm{MPa}$, and the interface oxidation ratio decreases from $\zeta / l_{\mathrm{d}}=40.7 \%$ to $\zeta / l_{\mathrm{d}}=26.5 \%$. At $T=1073 \mathrm{~K}$ and $t=1 \mathrm{~h}$, the matrix multi-cracking density increases from $\varphi=0.15 / \mathrm{mm}$ at $\sigma_{\mathrm{cr}}=132 \mathrm{MPa}$ to $\varphi=7 / \mathrm{mm}$ at $\sigma_{\text {sat }}=198 \mathrm{MPa}$, and the interface oxidation ratio decreases from $\zeta / l_{\mathrm{d}}=36.9 \%$ to $\zeta / l_{\mathrm{d}}=22.4 \%$; and at $t=3 \mathrm{~h}$, the matrix multi-cracking density increases from $\varphi=$ $=0.09 / \mathrm{mm}$ at $\sigma_{\text {cr }}=132 \mathrm{MPa}$ to $\varphi=4.8 / \mathrm{mm}$ at $\sigma_{\text {sat }}=$ $=198 \mathrm{MPa}$, and the interface oxidation ratio decreases from $\zeta / l_{\mathrm{d}}=71 \%$ to $\zeta / l_{\mathrm{d}}=50.1 \%$.

\section{Effect of the fibre/matrix interface de-bonded energy}

The effect of the fibre/matrix interface de-bonded energy (i.e., $\gamma_{\mathrm{d}}=0.3,0.5$ and $0.7 \mathrm{~J} \cdot \mathrm{m}^{-2}$ ) on the timedependent matrix multi-cracking and the fibre/matrix interface oxidation ratio of the $\mathrm{SiC} / \mathrm{SiC}$ composite at $T=873 \mathrm{~K}, 973 \mathrm{~K}$ and $1073 \mathrm{~K}$ for $t=1 \mathrm{~h}$ and $3 \mathrm{~h}$ are shown in Figure 6.

When $\gamma_{\mathrm{d}}=0.3 \mathrm{~J} \cdot \mathrm{m}^{-2}$ at $T=873 \mathrm{~K}$ and $t=1 \mathrm{~h}$, the matrix multi-cracking density increases from $\varphi=0.7 / \mathrm{mm}$ at $\sigma_{\mathrm{cr}}=146 \mathrm{MPa}$ to $\varphi=10.3 / \mathrm{mm}$ at $\sigma_{\text {sat }}=160 \mathrm{MPa}$, and the interface oxidation ratio decreases from $\zeta / l_{\mathrm{d}}=5.2 \%$ to $\zeta / l_{\mathrm{d}}=3.1 \%$; and at $t=3 \mathrm{~h}$, the matrix multi-cracking density increases from $\varphi=0.49 / \mathrm{mm}$ at $\sigma_{\mathrm{cr}}=146 \mathrm{MPa}$ to $\varphi=9.4 / \mathrm{mm}$ at $\sigma_{\text {sat }}=164 \mathrm{MPa}$, and the interface oxidation ratio decreases from $\zeta / l_{\mathrm{d}}=14.7 \%$ to $\zeta / l_{\mathrm{d}}=9.0 \%$. At $T=973 \mathrm{~K}$ and $t=1 \mathrm{~h}$, the matrix multi-cracking density increases from $\varphi=0.24 / \mathrm{mm}$ at $\sigma_{\mathrm{cr}}=134 \mathrm{MPa}$ to $\varphi=8.4 / \mathrm{mm}$ at $\sigma_{\text {sat }}=171 \mathrm{MPa}$, and the interface oxidation ratio decreases from $\zeta / l_{\mathrm{d}}=14.7 \%$ to $\zeta / l_{\mathrm{d}}=8.7 \%$; and at $t=3 \mathrm{~h}$, the matrix multi-cracking density increases from $\varphi=0.16 / \mathrm{mm}$ at $\sigma_{\mathrm{cr}}=134 \mathrm{MPa}$ to $\varphi=6.9 / \mathrm{mm}$ at $\sigma_{\text {sat }}=179 \mathrm{MPa}$, and the interface oxidation ratio decreases from $\zeta / l_{\mathrm{d}}=36.5 \%$ to $\zeta / l_{\mathrm{d}}=23.3 \%$. At $T=1073 \mathrm{~K}$ and $t=1 \mathrm{~h}$, the matrix multi-cracking density increases from $\varphi=0.15 / \mathrm{mm}$ at $\sigma_{\mathrm{cr}}=122 \mathrm{MPa}$ to $\varphi=6.7 / \mathrm{mm}$ at $\sigma_{\text {sat }}=183 \mathrm{MPa}$, and the interface oxidation ratio decreases from $\zeta / l_{\mathrm{d}}=32.6 \%$ to $\zeta / l_{\mathrm{d}}=19.6 \%$; and at $t=3 \mathrm{~h}$, the matrix multi-cracking density increases from $\varphi=0.09 / \mathrm{mm}$ at $\sigma_{\mathrm{cr}}=122 \mathrm{MPa}$ to $\varphi=4.8 / \mathrm{mm}$ at $\sigma_{\text {sat }}=183 \mathrm{MPa}$, and the interface oxidation ratio decreases from $\zeta / l_{\mathrm{d}}=67.3 \%$ to $\zeta / l_{\mathrm{d}}=46.3 \%$.

When $\gamma_{\mathrm{d}}=0.5 \mathrm{~J} \cdot \mathrm{m}^{-2}$ at $T=873 \mathrm{~K}$ and $t=1 \mathrm{~h}$, the matrix multi-cracking density increases from $\varphi=0.3 / \mathrm{mm}$ at $\sigma_{\mathrm{cr}}=146 \mathrm{MPa}$ to $\varphi=10.3 / \mathrm{mm}$ at $\sigma_{\text {sat }}=173 \mathrm{MPa}$, and the interface oxidation ratio decreases from $\zeta / l_{\mathrm{d}}=5.9 \%$ to $\zeta / l_{\mathrm{d}}=3.3 \%$; and at $t=3 \mathrm{~h}$, the matrix multi-cracking density increases from $\varphi=0.29 / \mathrm{mm}$ at $\sigma_{\mathrm{cr}}=146 \mathrm{MPa}$ to $\varphi=9.4 / \mathrm{mm}$ at $\sigma_{\text {sat }}=176 \mathrm{MPa}$, and the interface oxidation ratio decreases from $\zeta / l_{\mathrm{d}}=16.5 \%$ to $\zeta / l_{\mathrm{d}}=9.6 \%$. At $T=973 \mathrm{~K}$ and $t=1 \mathrm{~h}$, the matrix multi-cracking density increases from $\varphi=0.2 / \mathrm{mm}$ at $\sigma_{\text {cr }}=134 \mathrm{MPa}$ to $\varphi=$ $=8.4 / \mathrm{mm}$ at $\sigma_{\text {sat }}=184 \mathrm{MPa}$, and the interface oxidation ratio decreases from $\zeta / l_{\mathrm{d}}=17.1 \%$ to $\zeta / l_{\mathrm{d}}=9.5 \%$; and at $t=3 \mathrm{~h}$, the matrix multi-cracking density increases from $\varphi=0.15 / \mathrm{mm}$ at $\sigma_{\mathrm{cr}}=134 \mathrm{MPa}$ to $\varphi=6.9 / \mathrm{mm}$ at $\sigma_{\text {sat }}=192 \mathrm{MPa}$, and the interface oxidation ratio decreases from $\zeta / l_{\mathrm{d}}=41.2 \%$ to $\zeta / l_{\mathrm{d}}=25.2 \%$. At $T=1073 \mathrm{~K}$ and $t=1 \mathrm{~h}$, the matrix multi-cracking density increases from $\varphi=0.15 / \mathrm{mm}$ at $\sigma_{\text {cr }}=122 \mathrm{MPa}$ to $\varphi=6.7 / \mathrm{mm}$ at $\sigma_{\text {sat }}=183 \mathrm{MPa}$, and the interface oxidation ratio decreases from $\zeta / l_{\mathrm{d}}=38.9 \%$ to $\zeta / l_{\mathrm{d}}=21.7 \%$; and at $t=3 \mathrm{~h}$, the matrix multi-cracking density increases from $\varphi=0.09 / \mathrm{mm}$ at $\sigma_{\text {cr }}=122 \mathrm{MPa}$ to $\varphi=4.8 / \mathrm{mm}$ at $\sigma_{\text {sat }}=183 \mathrm{MPa}$, and the interface oxidation ratio decreases from $\zeta / l_{\mathrm{d}}=75.6 \%$ to $\zeta / l_{\mathrm{d}}=50 \%$.

When $\gamma_{\mathrm{d}}=0.7 \mathrm{~J} \cdot \mathrm{m}^{-2}$ at $T=873 \mathrm{~K}$ and $t=1 \mathrm{~h}$, the matrix multi-cracking density increases from $\varphi=0.3 / \mathrm{mm}$ at $\sigma_{\text {cr }}=146 \mathrm{MPa}$ to $\varphi=10.3 / \mathrm{mm}$ at $\sigma_{\text {sat }}=183 \mathrm{MPa}$, and the interface oxidation ratio decreases from $\zeta / l_{\mathrm{d}}=6.7 \%$ to $\zeta / l_{\mathrm{d}}=3.6 \%$; and at $t=3 \mathrm{~h}$, the matrix multi-cracking density increases from $\varphi=0.24 / \mathrm{mm}$ at $\sigma_{\mathrm{cr}}=146 \mathrm{MPa}$ to $\varphi=9.4 / \mathrm{mm}$ at $\sigma_{\text {sat }}=186 \mathrm{MPa}$, and the interface oxidation ratio decreases from $\zeta / l_{\mathrm{d}}=18.2 \%$ to $\zeta / l_{\mathrm{d}}=10.2 \%$. At $T=973 \mathrm{~K}$ and $t=1 \mathrm{~h}$, the matrix multi-cracking density increases from $\varphi=0.2 / \mathrm{mm}$ at $\sigma_{\text {cr }}=134 \mathrm{MPa}$ to $\varphi=8.4 / \mathrm{mm}$ at $\sigma_{\text {sat }}=202 \mathrm{MPa}$, and the interface oxidation ratio decreases from $\zeta / l_{\mathrm{d}}=19.7 \%$ to $\zeta / l_{\mathrm{d}}=10.3 \%$; and at $t=3 \mathrm{~h}$, the matrix multi-cracking density increases from $\varphi=0.15 / \mathrm{mm}$ at $\sigma_{\mathrm{cr}}=134 \mathrm{MPa}$ to $\varphi=6.9 / \mathrm{mm}$ at $\sigma_{\text {sat }}=202 \mathrm{MPa}$, and the interface oxidation ratio decreases from $\zeta / l_{\mathrm{d}}=46 \%$ to $\zeta / l_{\mathrm{d}}=27 \%$. At $T=1073 \mathrm{~K}$ and $t=1 \mathrm{~h}$, the matrix multi-cracking density increases from 
$\varphi=0.16 / \mathrm{mm}$ at $\sigma_{\text {cr }}=122 \mathrm{MPa}$ to $\varphi=6.8 / \mathrm{mm}$ at $\sigma_{\text {sat }}=$ $=183 \mathrm{MPa}$, and the interface oxidation ratio decreases from $\zeta / l_{\mathrm{d}}=46 \%$ to $\zeta / l_{\mathrm{d}}=23.8 \%$; and at $t=3 \mathrm{~h}$, the matrix multi-cracking density increases from $\varphi=0.09 / \mathrm{mm}$

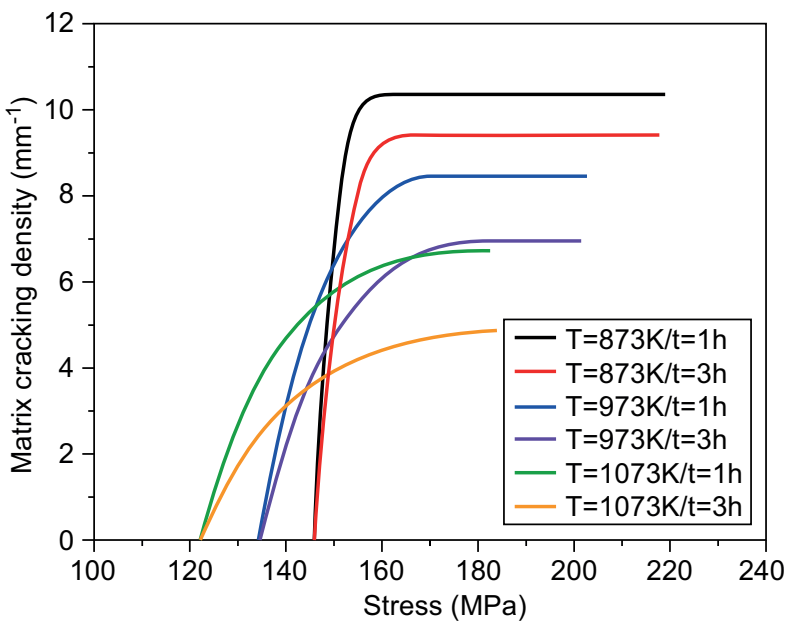

a) $\gamma_{\mathrm{d}}=0.3 \mathrm{~J} \cdot \mathrm{m}^{-2}$

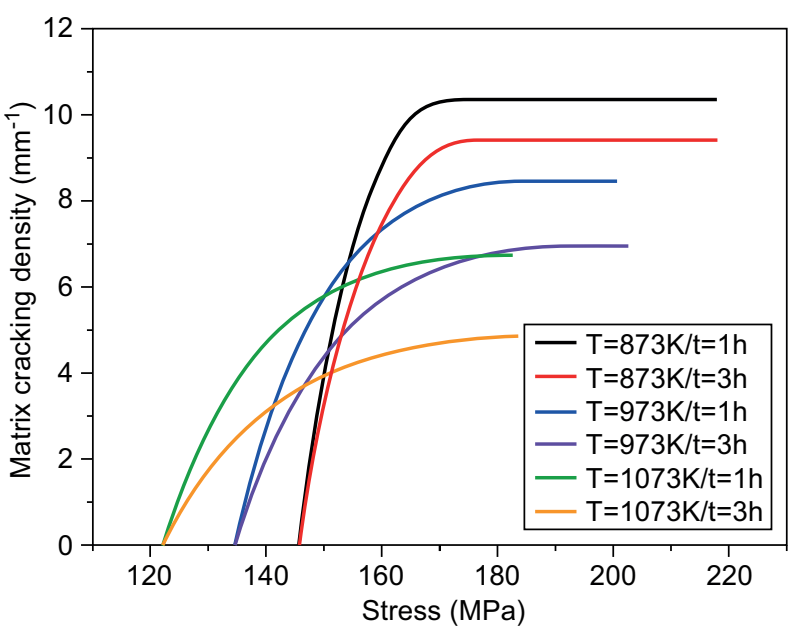

c) $\gamma_{\mathrm{d}}=0.5 \mathrm{~J} \cdot \mathrm{m}^{-2}$

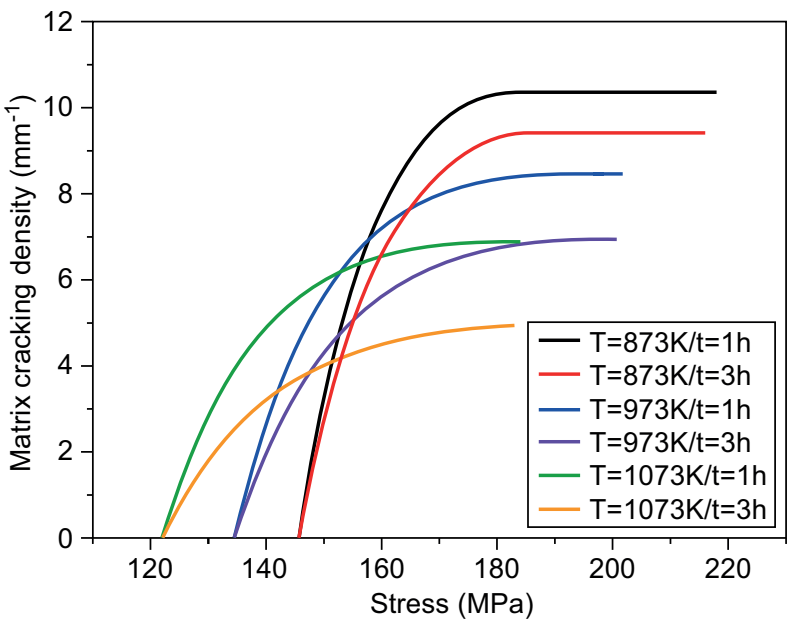

e) $\gamma_{\mathrm{d}}=0.7 \mathrm{~J} \cdot \mathrm{m}^{-2}$ at $\sigma_{\text {cr }}=122 \mathrm{MPa}$ to $\varphi=4.9 / \mathrm{mm}$ at $\sigma_{\text {sat }}=183 \mathrm{MPa}$, and the interface oxidation ratio decreases from $\zeta / l_{\mathrm{d}}=84.1 \%$ to $\zeta / l_{\mathrm{d}}=53.6 \%$.

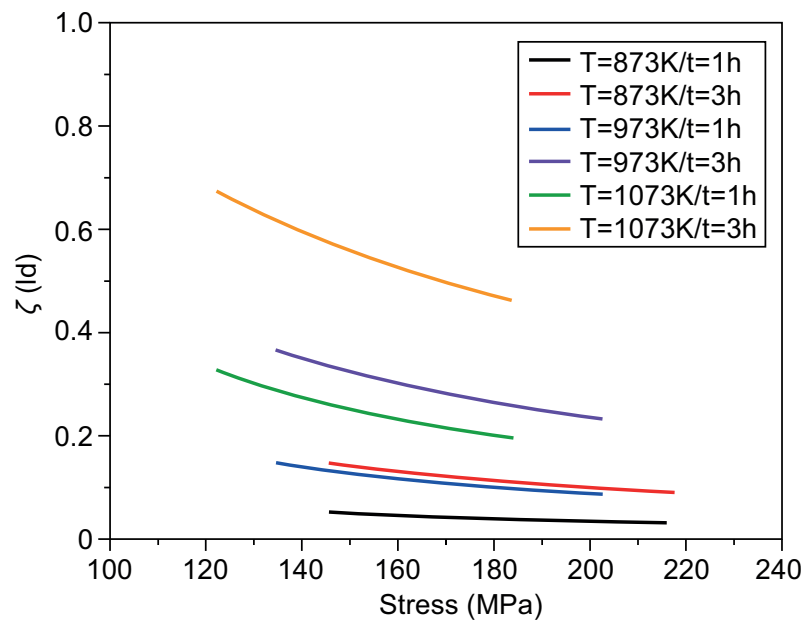

b) $\gamma_{\mathrm{d}}=0.3 \mathrm{~J} \cdot \mathrm{m}^{-2}$

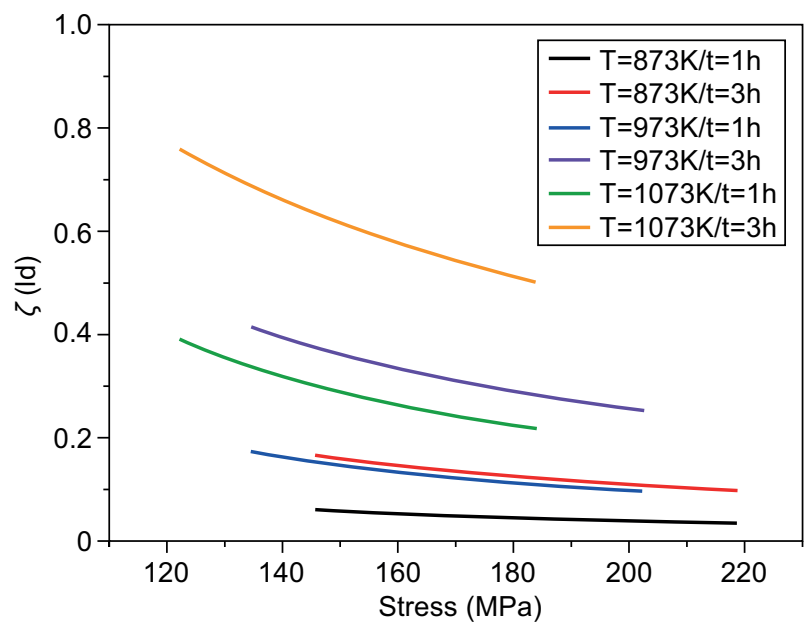

d) $\gamma_{\mathrm{d}}=0.5 \mathrm{~J} \cdot \mathrm{m}^{-2}$

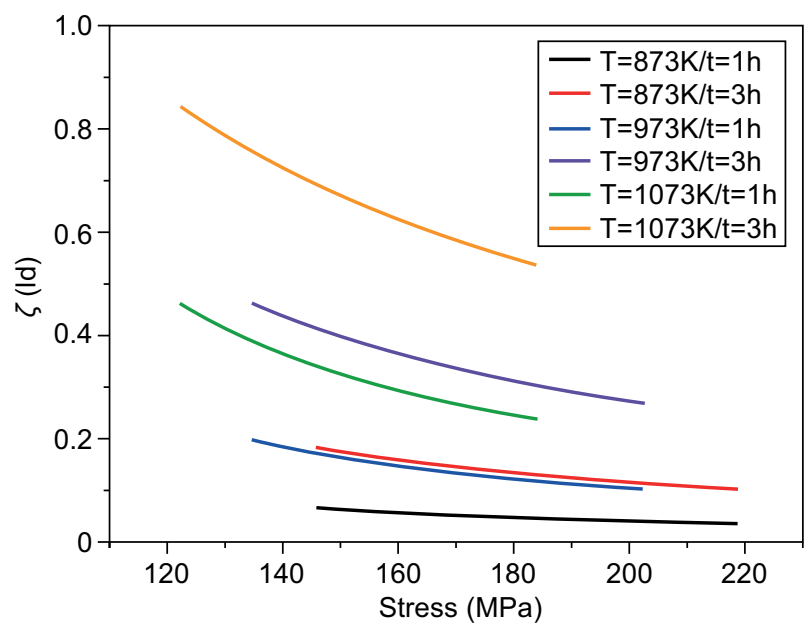

f) $\gamma_{\mathrm{d}}=0.7 \mathrm{~J} \cdot \mathrm{m}^{-2}$

Figure 6. The matrix cracking density versus the applied stress curves for the different oxidation temperature and time when $\gamma_{\mathrm{d}}=0.3 \mathrm{~J} \cdot \mathrm{m}^{-2}(\mathrm{a}), 0.5 \mathrm{~J} \cdot \mathrm{m}^{-2}(\mathrm{c}), 0.7 \mathrm{~J} \cdot \mathrm{m}^{-2}(\mathrm{e})$; the interface oxidation ratio versus the applied stress curves for the different oxidation temperature and time when $\gamma_{\mathrm{d}}=0.3 \mathrm{~J} \cdot \mathrm{m}^{-2}(\mathrm{~b}), 0.5 \mathrm{~J} \cdot \mathrm{m}^{-2}(\mathrm{~d}), 0.7 \mathrm{~J} \cdot \mathrm{m}^{-2}(\mathrm{f})$. 
Effect of the matrix fracture energy

The effect of the matrix fracture energy (i.e., $\gamma_{\mathrm{m}}=20$, 25 and $30 \mathrm{~J} \cdot \mathrm{m}^{-2}$ ) on the time-dependent matrix multicracking and the fibre/matrix interface oxidation ratio of

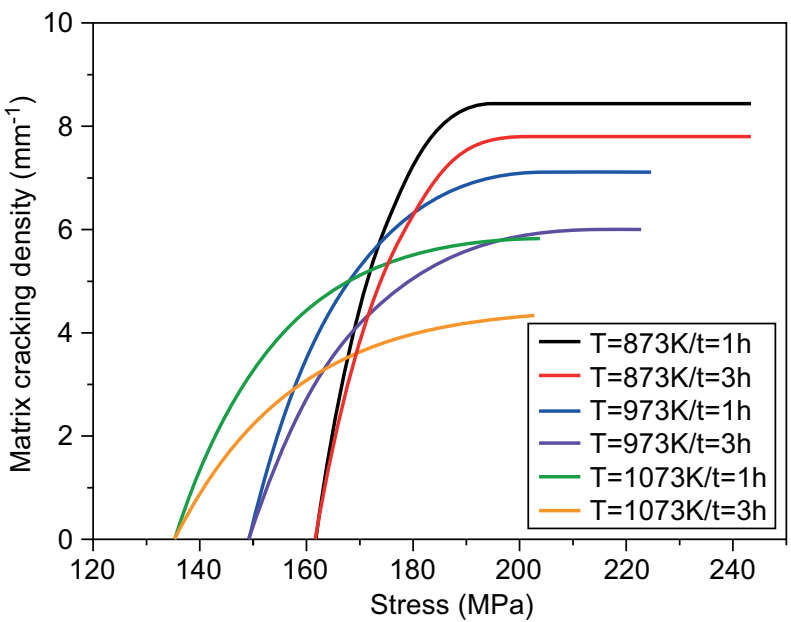

a) $\gamma_{\mathrm{m}}=20 \mathrm{~J} \cdot \mathrm{m}^{-2}$

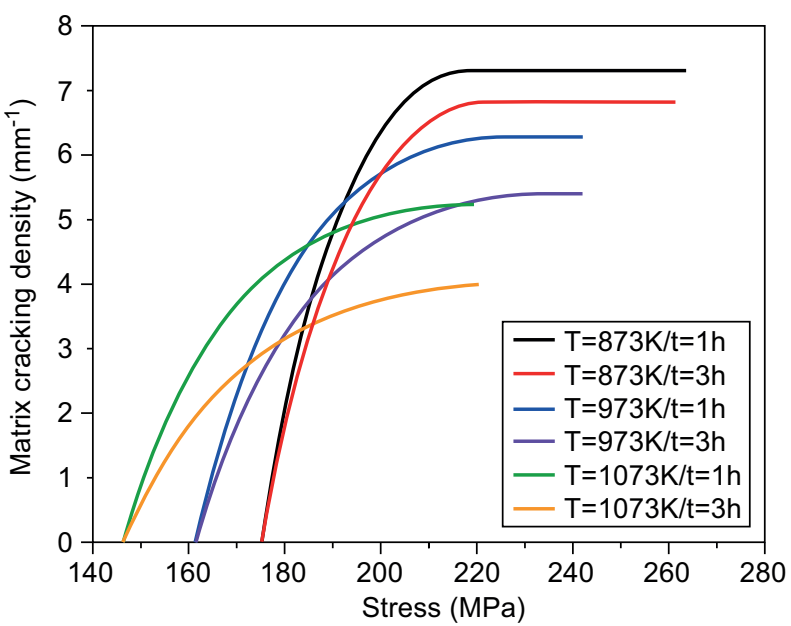

c) $\gamma_{\mathrm{m}}=25 \mathrm{~J} \cdot \mathrm{m}^{-2}$

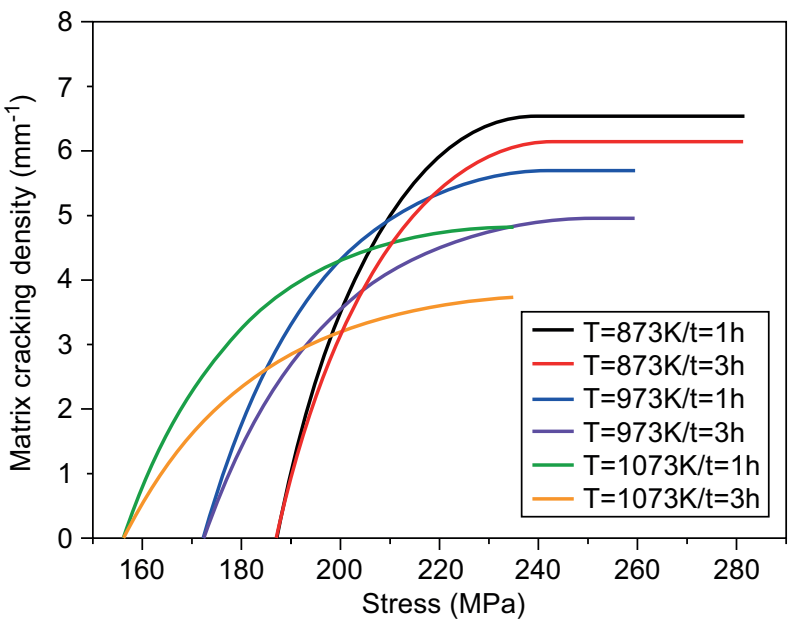

e) $\gamma_{\mathrm{m}}=30 \mathrm{~J} \cdot \mathrm{m}^{-2}$ the $\mathrm{SiC} / \mathrm{SiC}$ composite at $T=873 \mathrm{~K}, 973 \mathrm{~K}$ and $1073 \mathrm{~K}$ for $t=1 \mathrm{~h}$ and $3 \mathrm{~h}$ are shown in Figure 7.

When $\gamma_{\mathrm{m}}=20 \mathrm{~J} \cdot \mathrm{m}^{-2}$ at $T=873 \mathrm{~K}$ and $t=1 \mathrm{~h}$, the matrix multi-cracking density increases from $\varphi=0.3 / \mathrm{mm}$

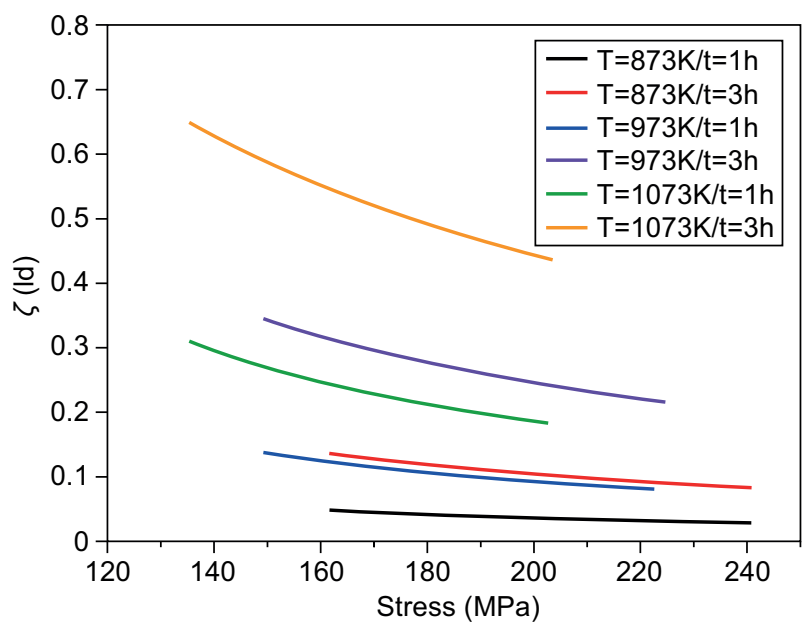

b) $\gamma_{\mathrm{m}}=20 \mathrm{~J} \cdot \mathrm{m}^{-2}$

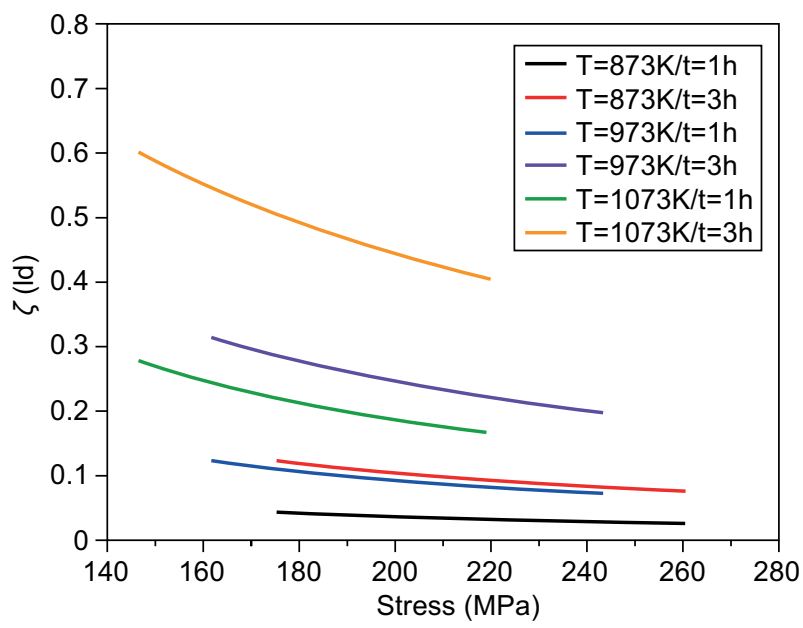

d) $\gamma_{\mathrm{m}}=25 \mathrm{~J} \cdot \mathrm{m}^{-2}$

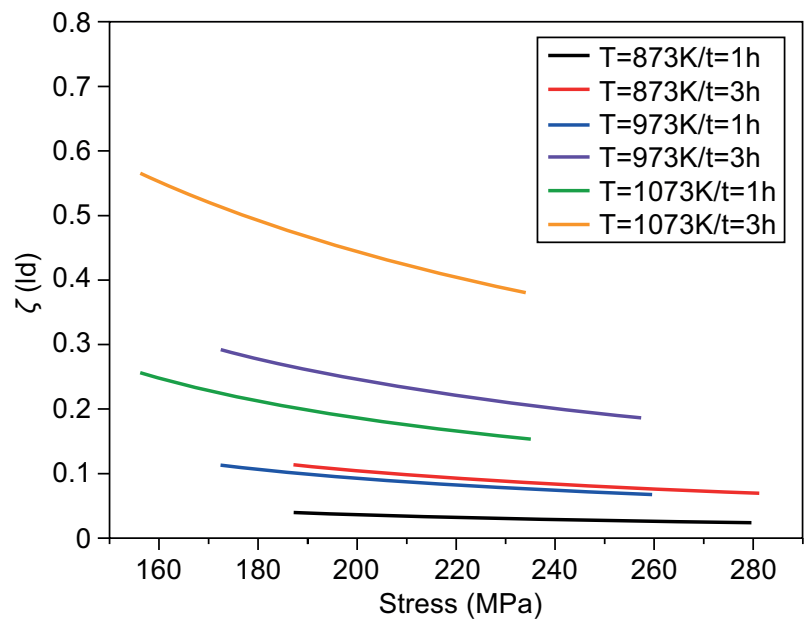

f) $\gamma_{\mathrm{m}}=30 \mathrm{~J} \cdot \mathrm{m}^{-2}$

Figure 7. The matrix cracking density versus the applied stress curves for the different oxidation temperature and time when $\gamma_{\mathrm{m}}=20 \mathrm{~J} \cdot \mathrm{m}^{-2}(\mathrm{a}), 25 \mathrm{~J} \cdot \mathrm{m}^{-2}(\mathrm{c}), 30 \mathrm{~J} \cdot \mathrm{m}^{-2}(\mathrm{e})$; the interface oxidation ratio versus the applied stress curves for the different oxidation temperature and time when $\gamma_{\mathrm{m}}=20 \mathrm{~J} \cdot \mathrm{m}^{-2}(\mathrm{~b}), 25 \mathrm{~J} \cdot \mathrm{m}^{-2}(\mathrm{~d}), 30 \mathrm{~J} \cdot \mathrm{m}^{-2}(\mathrm{f})$. 
at $\sigma_{\mathrm{cr}}=162 \mathrm{MPa}$ to $\varphi=8.4 / \mathrm{mm}$ at $\sigma_{\text {sat }}=195 \mathrm{MPa}$, and the interface oxidation ratio decreases from $\zeta / l_{\mathrm{d}}=4.8 \%$ to $\zeta / l_{\mathrm{d}}=2.8 \%$; and at $t=3 \mathrm{~h}$, the matrix multi-cracking density increases from $\varphi=0.24 / \mathrm{mm}$ at $\sigma_{\mathrm{cr}}=162 \mathrm{MPa}$ to $\varphi=7.8 / \mathrm{mm}$ at $\sigma_{\text {sat }}=199 \mathrm{MPa}$, and the interface oxidation ratio decreases from $\zeta / l_{\mathrm{d}}=13.6 \%$ to $\zeta / l_{\mathrm{d}}=8.2 \%$. At $T=973 \mathrm{~K}$ and $t=1 \mathrm{~h}$, the matrix multi-cracking density increases from $\varphi=0.18 / \mathrm{mm}$ at $\sigma_{\text {cr }}=149 \mathrm{MPa}$ to $\varphi=7.1 / \mathrm{mm}$ at $\sigma_{\text {sat }}=204 \mathrm{MPa}$, and the interface oxidation ratio decreases from $\zeta / l_{\mathrm{d}}=13.7 \%$ to $\zeta / l_{\mathrm{d}}=8 \%$; and at $t=3 \mathrm{~h}$, the matrix multi-cracking density increases from $\varphi=0.13 / \mathrm{mm}$ at $\sigma_{\mathrm{cr}}=149 \mathrm{MPa}$ to $\varphi=6 / \mathrm{mm}$ at $\sigma_{\text {sat }}=212 \mathrm{MPa}$, and the interface oxidation ratio decreases from $\zeta / l_{\mathrm{d}}=34.4 \%$ to $\zeta / l_{\mathrm{d}}=21.6 \%$. At $T=1073 \mathrm{~K}$ and $t=1 \mathrm{~h}$, the matrix multi-cracking density increases from $\varphi=0.13 / \mathrm{mm}$ at $\sigma_{\mathrm{cr}}=135 \mathrm{MPa}$ to $\varphi=5.8 / \mathrm{mm}$ at $\sigma_{\mathrm{sat}}=$ $=203 \mathrm{MPa}$, and the interface oxidation ratio decreases from $\zeta / l_{\mathrm{d}}=30.9 \%$ to $\zeta / l_{\mathrm{d}}=18.2 \%$; and at $t=3 \mathrm{~h}$, the matrix multi-cracking density increases from $\varphi=0.08 / \mathrm{mm}$ at $\sigma_{\text {cr }}=135 \mathrm{MPa}$ to $\varphi=4.3 / \mathrm{mm}$ at $\sigma_{\text {sat }}=203 \mathrm{MPa}$, and the interface oxidation ratio decreases from $\zeta / l_{\mathrm{d}}=64.7 \%$ to $\zeta / l_{\mathrm{d}}=43.6 \%$.

When $\gamma_{\mathrm{m}}=25 \mathrm{~J} \cdot \mathrm{m}^{-2}$ at $T=873 \mathrm{~K}$ and $t=1 \mathrm{~h}$, the matrix multi-cracking density increases from $\varphi=0.23 / \mathrm{mm}$ at $\sigma_{\text {cr }}=175 \mathrm{MPa}$ to $\varphi=7.3 / \mathrm{mm}$ at $\sigma_{\text {sat }}=218 \mathrm{MPa}$, and the interface oxidation ratio decreases from $\zeta / l_{\mathrm{d}}=4.3 \%$ to $\zeta / l_{\mathrm{d}}=2.6 \%$; and at $t=3 \mathrm{~h}$, the matrix multi-cracking density increases from $\varphi=0.2 / \mathrm{mm}$ at $\sigma_{\text {cr }}=175 \mathrm{MPa}$ to $\varphi=6.8 / \mathrm{mm}$ at $\sigma_{\text {sat }}=222 \mathrm{MPa}$, and the interface oxidation ratio decreases from $\zeta / l_{\mathrm{d}}=12.2 \%$ to $\zeta / l_{\mathrm{d}}=7.5 \%$. At $T=973 \mathrm{~K}$ and $t=1 \mathrm{~h}$, the matrix multi-cracking density increases from $\varphi=0.15 / \mathrm{mm}$ at $\sigma_{\text {cr }}=162 \mathrm{MPa}$ to $\varphi=6.2 / \mathrm{mm}$ at $\sigma_{\text {sat }}=243 \mathrm{MPa}$, and the interface oxidation ratio decreases from $\zeta / l_{\mathrm{d}}=12.3 \%$ to $\zeta / l_{\mathrm{d}}=7.3 \%$; and at $t=3 \mathrm{~h}$, the matrix multi-cracking density increases from $\varphi=0.12 / \mathrm{mm}$ at $\sigma_{\mathrm{cr}}=162 \mathrm{MPa}$ to $\varphi=5.4 / \mathrm{mm}$ at $\sigma_{\text {sat }}=234 \mathrm{MPa}$, and the interface oxidation ratio decreases from $\zeta / l_{\mathrm{d}}=31.3 \%$ to $\zeta / l_{\mathrm{d}}=19.8 \%$. At $T=1073 \mathrm{~K}$ and $t=1 \mathrm{~h}$, the matrix multi-cracking density increases from $\varphi=0.12 / \mathrm{mm}$ at $\sigma_{\mathrm{cr}}=146 \mathrm{MPa}$ to $\varphi=5.2 / \mathrm{mm}$ at $\sigma_{\text {sat }}=220 \mathrm{MPa}$, and the interface oxidation ratio decreases from $\zeta / l_{\mathrm{d}}=27.7 \%$ to $\zeta / l_{\mathrm{d}}=16.5 \%$; and at $t=3 \mathrm{~h}$, the matrix multi-cracking density increases from $\varphi=0.08 / \mathrm{mm}$ at $\sigma_{\text {cr }}=146 \mathrm{MPa}$ to $\varphi=4.0 / \mathrm{mm}$ at $\sigma_{\text {sat }}=220 \mathrm{MPa}$, and the interface oxidation ratio decreases from $\zeta / l_{\mathrm{d}}=60 \%$ to $\zeta / l_{\mathrm{d}}=40.4 \%$.

When $\gamma_{\mathrm{m}}=30 \mathrm{~J} \cdot \mathrm{m}^{-2}$ at $T=873 \mathrm{~K}$ and $t=1 \mathrm{~h}$, the matrix multi-cracking density increases from $\varphi=0.2 / \mathrm{mm}$ at $\sigma_{\text {cr }}=187 \mathrm{MPa}$ to $\varphi=6.5 / \mathrm{mm}$ at $\sigma_{\text {sat }}=239 \mathrm{MPa}$, and the interface oxidation ratio decreases from $\zeta / l_{\mathrm{d}}=4 \%$ to $\zeta / l_{\mathrm{d}}=2.4 \%$; and at $t=3 \mathrm{~h}$, the matrix multi-cracking density increases from $\varphi=0.17 / \mathrm{mm}$ at $\sigma_{\mathrm{cr}}=167 \mathrm{MPa}$ to $\varphi=6.1 / \mathrm{mm}$ at $\sigma_{\text {sat }}=242 \mathrm{MPa}$, and the interface oxidation ratio decreases from $\zeta / l_{\mathrm{d}}=11.3 \%$ to $\zeta / l_{\mathrm{d}}=6.9 \%$. At $T=973 \mathrm{~K}$ and $t=1 \mathrm{~h}$, the matrix multi-cracking density increases from $\varphi=0.14 / \mathrm{mm}$ at $\sigma_{\mathrm{cr}}=172 \mathrm{MPa}$ to $\varphi=5.6 / \mathrm{mm}$ at $\sigma_{\text {sat }}=243 \mathrm{MPa}$, and the interface oxidation ratio decreases from $\zeta / l_{\mathrm{d}}=11.2 \%$ to $\zeta / l_{\mathrm{d}}=6.7 \%$; and at $t=3 \mathrm{~h}$, the matrix multi-cracking density increases from $\varphi=0.11 / \mathrm{mm}$ at $\sigma_{\mathrm{cr}}=172 \mathrm{MPa}$ to $\varphi=4.9 / \mathrm{mm}$ at $\sigma_{\text {sat }}=253 \mathrm{MPa}$, and the interface oxidation ratio decreases from $\zeta / l_{\mathrm{d}}=29.1 \%$ to $\zeta / l_{\mathrm{d}}=18.4 \%$. At $T=1073 \mathrm{~K}$ and $t=1 \mathrm{~h}$, the matrix multi-cracking density increases from $\varphi=0.11 / \mathrm{mm}$ at $\sigma_{\text {cr }}=156 \mathrm{MPa}$ to $\varphi=4.8 / \mathrm{mm}$ at $\sigma_{\text {sat }}=$ $=234 \mathrm{MPa}$, and the interface oxidation ratio decreases from $\zeta / l_{\mathrm{d}}=25.4 \%$ to $\zeta / l_{\mathrm{d}}=15.3 \%$; and at $t=3 \mathrm{~h}$, the matrix multi-cracking density increases from $\varphi=0.07 / \mathrm{mm}$ at $\sigma_{\text {cr }}=156 \mathrm{MPa}$ to $\varphi=3.7 / \mathrm{mm}$ at $\sigma_{\text {sat }}=234 \mathrm{MPa}$, and the interface oxidation ratio decreases from $\zeta / l_{\mathrm{d}}=56.3 \%$ to $\zeta / l_{\mathrm{d}}=37.9 \%$.

\section{EXPERIMENTAL COMPARISONS}

The experimental and theoretical matrix multicracking density and the fibre/matrix interface oxidation ratio of the unidirectional $\mathrm{SiC} / \mathrm{SiC}$ [29] and mini $\mathrm{SiC} / \mathrm{SiC}[30]$ composites composite at room temperature, $T=773 \mathrm{~K}, 873 \mathrm{~K}, 973 \mathrm{~K}$ and $1073 \mathrm{~K}$ for $t=1 \mathrm{~h}$ and $3 \mathrm{~h}$ are predicted, as shown in Figures 8 and 9.

\section{The unidirectional $\mathrm{SiC} / \mathrm{SiC}$ composite}

Beyerle et al. [29] investigated the damage evolution of the matrix multi-cracking in the unidirectional $\mathrm{SiC} /$ $\mathrm{SiC}$ composite. At room temperature, the matrix multicracking evolution starts at $\sigma_{\mathrm{cr}}=240 \mathrm{MPa}$ and approaches saturation at $\sigma_{\text {sat }}=320 \mathrm{MPa}$; and the matrix cracking density increases from $\varphi=1.1 / \mathrm{mm}$ to $\varphi=13 / \mathrm{mm}$.

At $T=773 \mathrm{~K}$, the matrix multi-cracking density increases from $\varphi=0.5 / \mathrm{mm}$ at $\sigma_{\mathrm{cr}}=222 \mathrm{MPa}$ to $\varphi=12.4 / \mathrm{mm}$ at $\sigma_{\text {sat }}=311 \mathrm{MPa}$; at $T=773 \mathrm{~K}$ and $\mathrm{t}=1 \mathrm{~h}$, the matrix multi-cracking density increases from $\varphi=0.36 / \mathrm{mm}$ at $\sigma_{\text {cr }}=222 \mathrm{MPa}$ to $\varphi=11.9 / \mathrm{mm}$ at $\sigma_{\text {sat }}=272 \mathrm{MPa}$, and the interface oxidation ratio decreases from $\zeta / l_{\mathrm{d}}=2 \%$ at $\sigma_{\mathrm{cr}}=222 \mathrm{MPa}$ to $\zeta / l_{\mathrm{d}}=1.1 \%$ at $\sigma_{\text {sat }}=272 \mathrm{MPa}$; and at $T=773 \mathrm{~K}$ and $\mathrm{t}=3 \mathrm{~h}$, the matrix multi-cracking density increases from $\varphi=0.34 / \mathrm{mm}$ at $\sigma_{\mathrm{cr}}=222 \mathrm{MPa}$ to $\varphi=11.5 / \mathrm{mm}$ at $\sigma_{\text {sat }}=273 \mathrm{MPa}$, and the interface oxidation ratio decreases from $\zeta / l_{\mathrm{d}}=5.8 \%$ at $\sigma_{\mathrm{cr}}=222 \mathrm{MPa}$ to $\zeta / l_{\mathrm{d}}=3.4 \%$ at $\sigma_{\text {sat }}=273 \mathrm{MPa}$.

At $T=873 \mathrm{~K}$, the matrix multi-cracking density increases from $\varphi=0.45 / \mathrm{mm}$ at $\sigma_{\mathrm{cr}}=206 \mathrm{MPa}$ to $\varphi=$ $=11.2 / \mathrm{mm}$ at $\sigma_{\text {sat }}=288 \mathrm{MPa}$; at $T=873 \mathrm{~K}$ and $t=1 \mathrm{~h}$, the matrix multi-cracking density increases from $\varphi=0.25 / \mathrm{mm}$ at $\sigma_{\text {cr }}=206 \mathrm{MPa}$ to $\varphi=10.3 / \mathrm{mm}$ at $\sigma_{\text {sat }}=288 \mathrm{MPa}$, and the interface oxidation ratio decreases from $\zeta / l_{\mathrm{d}}=8.3 \%$ at $\sigma_{\mathrm{cr}}=206 \mathrm{MPa}$ to $\zeta / l_{\mathrm{d}}=4.6 \%$ at $\sigma_{\text {sat }}=288 \mathrm{MPa}$; and at $T=873 \mathrm{~K}$ and $t=3 \mathrm{~h}$, the matrix multi-cracking density increases from $\varphi=0.21 / \mathrm{mm}$ at $\sigma_{\text {cr }}=206 \mathrm{MPa}$ to $\varphi=9.4 / \mathrm{mm}$ at $\sigma_{\text {sat }}=288 \mathrm{MPa}$, and the interface oxidation ratio decreases from $\zeta / l_{\mathrm{d}}=22.3 \%$ at $\sigma_{\mathrm{cr}}=206 \mathrm{MPa}$ to $\zeta / l_{\mathrm{d}}=13 \%$ at $\sigma_{\text {sat }}=288 \mathrm{MPa}$. 
At $T=973 \mathrm{~K}$, the matrix multi-cracking density increases from $\varphi=0.4 / \mathrm{mm}$ at $\sigma_{\mathrm{cr}}=188 \mathrm{MPa}$ to $\varphi=10.2 / \mathrm{mm}$ at $\sigma_{\text {sat }}=263 \mathrm{MPa}$; at $T=973 \mathrm{~K}$ and $t=1 \mathrm{~h}$, the matrix multi-cracking density increases from $\varphi=0.21 / \mathrm{mm}$ at $\sigma_{\text {cr }}=188 \mathrm{MPa}$ to $\varphi=8.8 / \mathrm{mm}$ at $\sigma_{\text {sat }}=263 \mathrm{MPa}$, and the interface oxidation ratio decreases from $\zeta / l_{\mathrm{d}}=26.3 \%$ at $\sigma_{\text {cr }}=188 \mathrm{MPa}$ to $\zeta / l_{\mathrm{d}}=13.7 \%$ at $\sigma_{\text {sat }}=263 \mathrm{MPa}$; and at $T=973 \mathrm{~K}$ and $t=3 \mathrm{~h}$, the matrix multi-cracking density increases from $\varphi=0.15 / \mathrm{mm}$ at $\sigma_{\mathrm{cr}}=188 \mathrm{MPa}$ to $\varphi=7.1 / \mathrm{mm}$ at $\sigma_{\text {sat }}=263 \mathrm{MPa}$, and the interface oxidation ratio decreases from $\zeta / l_{\mathrm{d}}=57.2 \%$ at $\sigma_{\mathrm{cr}}=188 \mathrm{MPa}$ to $\zeta / l_{\mathrm{d}}=$ $=34.5 \%$ at $\sigma_{\text {sat }}=263 \mathrm{MPa}$.

At $T=1073 \mathrm{~K}$, the matrix multi-cracking density increases from $\varphi=0.35 / \mathrm{mm}$ at $\sigma_{\mathrm{cr}}=169 \mathrm{MPa}$ to $\varphi=9.4 / \mathrm{mm}$ at $\sigma_{\text {sat }}=236 \mathrm{MPa}$; at $T=1073 \mathrm{~K}$ and $t=1 \mathrm{~h}$, the matrix multi-cracking density increases from $\varphi=0.2 / \mathrm{mm}$ at $\sigma_{\mathrm{cr}}=169 \mathrm{MPa}$ to $\varphi=7.7 / \mathrm{mm}$ at $\sigma_{\text {sat }}=236 \mathrm{MPa}$, and the interface oxidation ratio decreases from $\zeta / l_{\mathrm{d}}=65.7 \%$ at $\sigma_{\mathrm{cr}}=169 \mathrm{MPa}$ to $\zeta / l_{\mathrm{d}}=33.2 \%$ at $\sigma_{\text {sat }}=236 \mathrm{MPa}$; and at $T=1073 \mathrm{~K}$ and $t=3 \mathrm{~h}$, the matrix multi-cracking density increases from $\varphi=0.11 / \mathrm{mm}$ at $\sigma_{\mathrm{cr}}=169 \mathrm{MPa}$ to $\varphi=5.2 / \mathrm{mm}$ at $\sigma_{\text {sat }}=236 \mathrm{MPa}$, and the interface oxidation ratio decreases from $\zeta / l_{\mathrm{d}}=1$ at $\sigma_{\mathrm{cr}}=169 \mathrm{MPa}$ to $\zeta / l_{\mathrm{d}}=68.1 \%$ at $\sigma_{\text {sat }}=236 \mathrm{MPa}$.

\section{The mini $\mathrm{SiC} / \mathrm{SiC}$ composite}

Zhang et al. [30] investigated the damage evolution of the matrix multi-cracking in the mini-SiC/SiC composite. At room temperature, the matrix multi-cracking evolution starts from the applied stress of $\sigma_{\mathrm{cr}}=135 \mathrm{MPa}$ and approaches saturation at $\sigma_{\text {sat }}=250 \mathrm{MPa}$; the matrix multi-cracking density increases from $\varphi=0.4 / \mathrm{mm}$ to $\varphi=$ $=2.4 / \mathrm{mm}$.

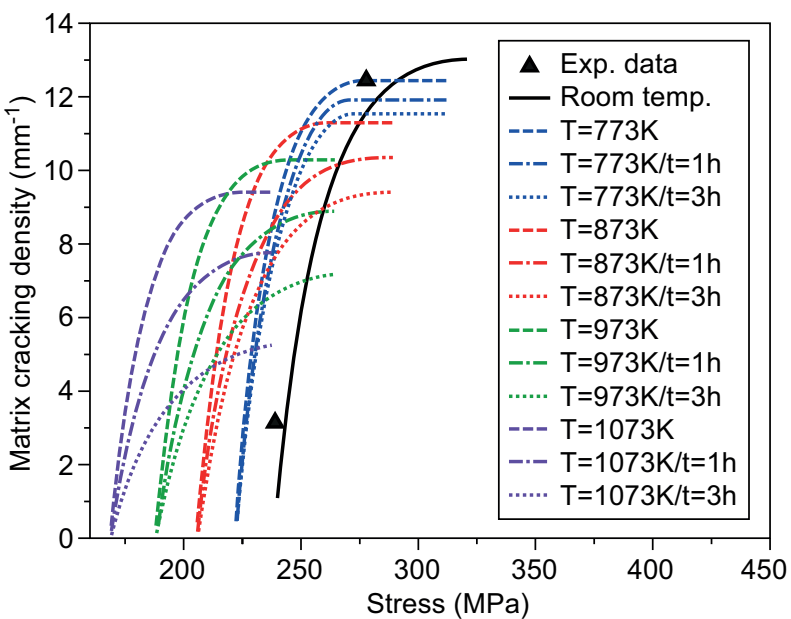

a)

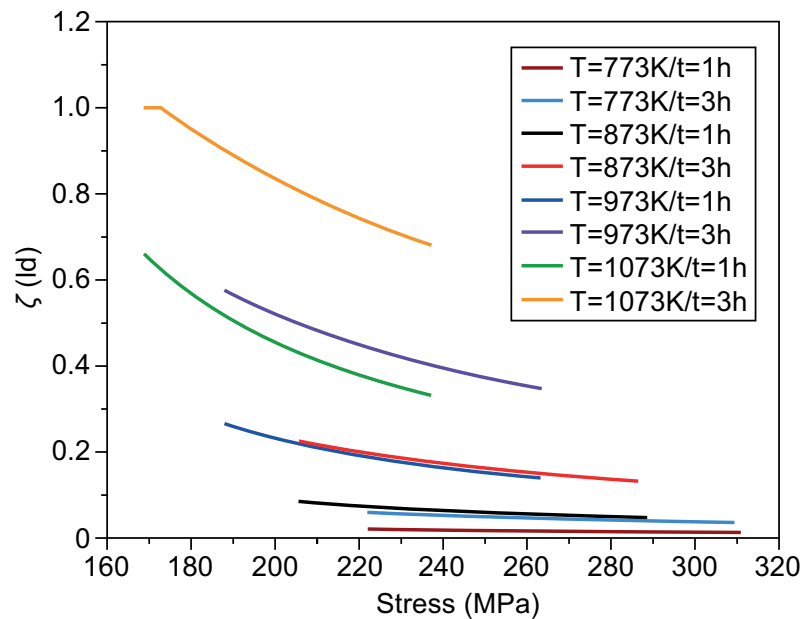

b)

Figure 8. The experimental and theoretical matrix cracking density versus the applied stress curves for the different oxidation temperature and time (a); the interface oxidation ratio versus the applied stress curves for the different oxidation temperature and time of the unidirectional $\mathrm{SiC} / \mathrm{SiC}$ composite (b).

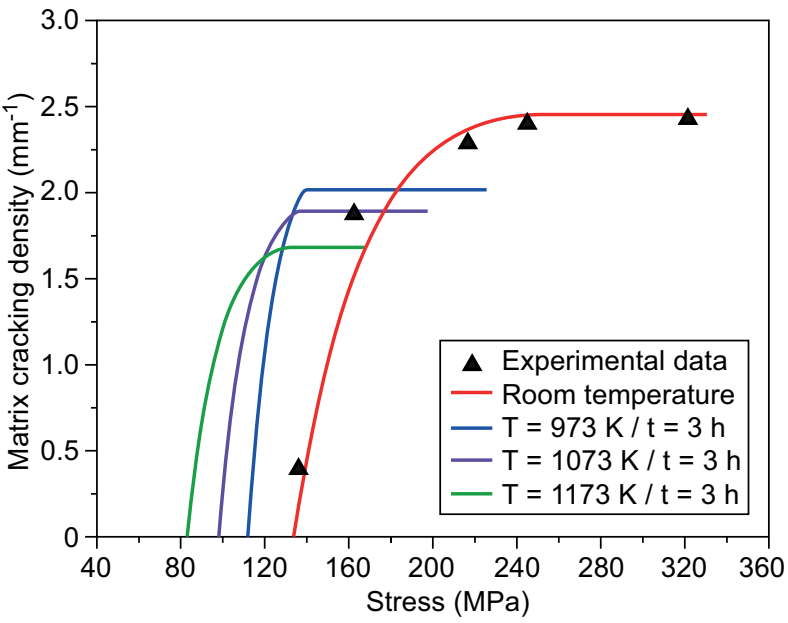

a)

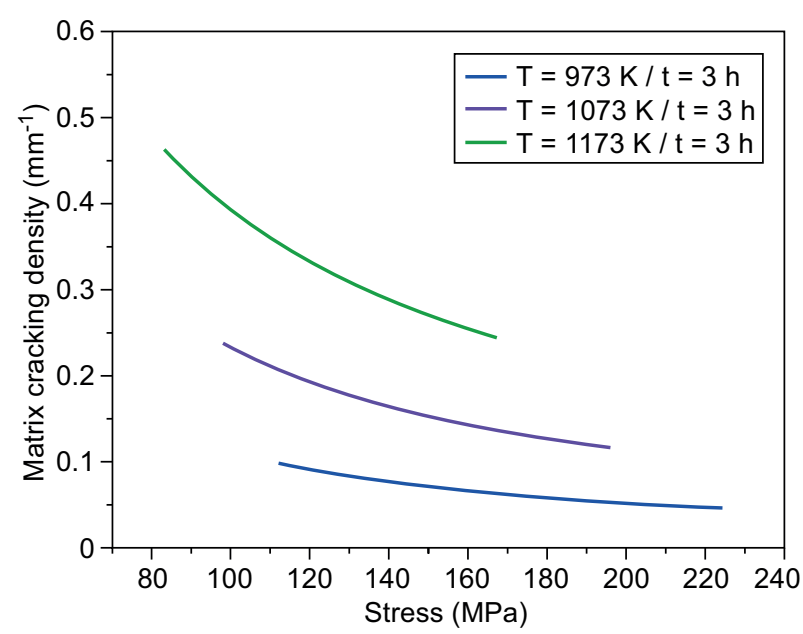

b)

Figure 9. The experimental and theoretical matrix cracking density versus the applied stress curves for the different oxidation temperature and time (a); the interface oxidation ratio versus the applied stress curves for the different oxidation temperature and time of the mini $\mathrm{SiC} / \mathrm{SiC}$ composite (b). 
At $T=973 \mathrm{~K}$ and $t=3 \mathrm{~h}$, the matrix multi-cracking density increases from $\varphi=0.06 / \mathrm{mm}$ at $\sigma_{\mathrm{cr}}=112 \mathrm{MPa}$ to $\varphi=2 / \mathrm{mm}$ at $\sigma_{\text {sat }}=140 \mathrm{MPa}$, and the interface oxidation ratio decreases from $\zeta / l_{\mathrm{d}}=9.8 \%$ to $\zeta / l_{\mathrm{d}}=4.6 \%$.

At $T=1073 \mathrm{~K}$ and $t=3 \mathrm{~h}$, the matrix multi-cracking density increases from $\varphi=0.04 / \mathrm{mm}$ at $\sigma_{\text {cr }}=98.4 \mathrm{MPa}$ to $\varphi=1.9 / \mathrm{mm}$ at $\sigma_{\text {sat }}=136 \mathrm{MPa}$, and the interface oxidation ratio decreases from $\zeta / l_{\mathrm{d}}=23.7 \%$ to $\zeta / l_{\mathrm{d}}=11.6 \%$.

At $T=1173 \mathrm{~K}$ and $t=3 \mathrm{~h}$, the matrix multi-cracking density increases from $\varphi=0.03 / \mathrm{mm}$ at $\sigma_{\mathrm{cr}}=83.4 \mathrm{MPa}$ to $\varphi=1.7 / \mathrm{mm}$ at $\sigma_{\text {sat }}=133 \mathrm{MPa}$, and the interface oxidation ratio decreases from $\zeta / l_{\mathrm{d}}=46.2 \%$ to $\zeta / l_{\mathrm{d}}=24.5 \%$.

\section{CONCLUSIONS}

In this paper, the time-dependent matrix multicracking of $\mathrm{SiC} / \mathrm{SiC}$ composite has been investigated considering the fibre/matrix interface oxidation. The effects of the fibre volume fraction, the fibre/matrix interface shear stress, the fibre/matrix interface frictional coefficient, the fibre/matrix interface de-bonded energy and the matrix fracture energy on the matrix multicracking density and the fibre/matrix interface oxidation ratio of the $\mathrm{SiC} / \mathrm{SiC}$ composite have been discussed for the different temperatures and oxidation time. The experimental matrix multi-cracking density and the fibre/ matrix interface oxidation ratio for the unidirectional and mini $\mathrm{SiC} / \mathrm{SiC}$ composite at the different testing temperatures and oxidation time have been predicted. With an increasing temperature, the first matrix cracking stress of the $\mathrm{SiC} / \mathrm{SiC}$ composite decreases due to the decreasing of the fibre/matrix interface shear stress in the de-bonded region.

With an increasing of oxidation time at an elevated temperature, the saturation matrix cracking density of the $\mathrm{SiC} / \mathrm{SiC}$ composite decreases, due to the decreasing of the interface shear stress in the oxidation region.

\section{Acknowledgements}

The work reported here is supported by the Fundamental Research Funds for the Central Universities (Grant No. NS2016070).

\section{REFERENCES}

1. Christin F. (2002): Design, fabrication, and application of thermostructural composites (TSC) like $\mathrm{C} / \mathrm{C}, \mathrm{C} / \mathrm{SiC}$, and $\mathrm{SiC} / \mathrm{SiC}$ composites. Advanced Engineering Materials, 4(12), 903-912. doi: 10.1002/adem.200290001

2. Naslain R. (2004): Design, preparation and properties of non-oxide CMCs for application in engines and nuclear reactors: an overview. Composites Science and Technology, 64(2), 155-170. doi: 10.1016/S0266-3538(03)00230-6
3. Zhu D. (2018). Aerospace ceramic materials: thermal, environmental barrier coatings and $\mathrm{SiC} / \mathrm{SiC}$ ceramic matrix composites for turbine engine applications. NASA/TM2018-219884.

4. Cox B. N., Marshall D. B. (1996): Crack Initiation in FiberReinforced Brittle Laminates. Journal of the American Ceramic Society, 79(5), 1181-1188. doi: 10.1111/j.11512916.1996.tb08570.x

5. Sevener K. M., Tracy J. M., Chen Z., Kiser J. D., Daly S. (2017): Crack opening behavior in ceramic matrix composites. Journal of the American Ceramic Society, 100(10), 4734-4747. doi: 10.1111/jace.14976

6. Filipuzzi L., Camus, G., Naslain R., Thebault J. (1994): Oxidation mechanisms and Kinetics of $1 \mathrm{D}-\mathrm{SiC} / \mathrm{c} / \mathrm{SiC}$ composite materials: I, an experimental approach. Journal of the American Ceramic Society, 77(2), 459-466. doi: 10.1111/ j.1151-2916.1994.tb07015.x

7. Lamouroux F., Naslain R., Jouin J. M. (1994): Kinetics and mechanisms of oxidation of $2 \mathrm{D}$ woven $\mathrm{C} / \mathrm{SiC}$ composites: II, theoretical approach. Journal of the American ceramic society, 77(8), 2058-2068. doi: 10.1111/j.1151-2916.1994. tb07097.x

8. Verrilli M. J., Opila E. J., Calomino A., Kiser J. D. (2004): Effect of Environment on the Stress-Rupture Behavior of a Carbon-Fiber-Reinforced Silicon Carbide Ceramic Matrix Composite. Journal of the American Ceramic Society, 87(8), 1536-1542. doi: 10.1111/j.1551-2916.2004.01536.x

9. Halbig M. C., McGuffin-Cawley J. D., Eckel A. J., Brewer D. N. (2008): Oxidation Kinetics and stress effects for the oxidation of continuous carbon fibers within a microcracked $\mathrm{C} / \mathrm{SiC}$ ceramic matrix composite. Journal of the American ceramic society, 91(2), 519-526. doi: 10.1111/j.1551-2916. 2007.02170.x

10. Li. L. (2017): Modeling matrix cracking of fiber-reinforced ceramic-matrix composites under oxidation environment at elevated temperature. Theoretical and Applied Fracture Mechanics, 87, 110-119. doi: 10.1016/j.tafmec.2016.11.003

11. Smith C. E., Morscher G. N., Xia Z. H. (2008): Monitoring damage accumulation in ceramic matrix composites using electrical resistivity. Scripta Materialia, 59(4), 463-466. doi: 10.1016/j.scriptamat.2008.04.033

12. Simon C., Rebillat F., Herb V., Camus G. (2017): Monitoring damage evolution of $\mathrm{SiCf} /[\mathrm{SiBC}] \mathrm{m}$ composites using electrical resistivity: Crack density-based electromechanical modeling. Acta Materialia, 124, 579-587. doi: 10.10 16/j.actamat.2016.11.036

13. Gowayed Y., Ojard G., Santhosh U., Jefferson G. (2015): Modeling of crack density in ceramic matrix composites. Journal of Composite Materials, 49(18), 2285-2294. doi: 10.1177/0021998314545188

14. Parthasarathy T. A., Cox B., Sudre O., Przybyla C., Cinibulk M. K. (2018): Modeling environmentally induced property degradation of $\mathrm{SiC} / \mathrm{BN} / \mathrm{SiC}$ ceramic matrix composites. Journal of the American Ceramic Society, 101(3), 973-997. doi: 10.1111 jace. 15325

15. Aveston J., Cooper G.A., Kelly A. (1971). The Properties of Fiber Composites. in: Proceedings of National Physical Laboratory. Guildford, IPC Science and Technology Press. pp. 15-26.

16. Beyerle D. S., Spearing S. M., Zok F. W., Evans A. G. (1992): Damage and failure in unidirectional ceramicmatrix composites. Journal of the American Ceramic Society, 75(10), 2719-2725. doi: 10.1111/j.1151-2916.1992. tb05495.x 
17. Holmes J. W., Cho C. (1992): Experimental Observations of Frictional Heating in Fiber-Reinforced Ceramics. Journal of the American Ceramic Society, 75(4), 929-938. doi: 10.1111/j.1151-2916.1992.tb04162.x

18. Kuo W. S., Chou T. W. (1995): Multiple Cracking of Unidirectional and Cross-PlyCeramic Matrix Composites. Journal of the American Ceramic Society, 78(3), 745-755. doi: 10.1111/j.1151-2916.1995.tb08242.x

19. Li L. (2017): Modeling first matrix cracking stress of fiberreinforced ceramic-matrix composites considering fiber fracture. Theoretical and Applied Fracture Mechanics, 92, 24-32. doi: 10.1016/j.tafmec.2017.05.004

20. Li L. (2017): Synergistic effects of fiber debonding and fracture on matrix cracking in fiber-reinforced ceramicmatrix composites. Materials Science and Engineering: A, 682, 482-490. doi: 10.1016/j.msea.2016.11.077

21. Li L. (2018). Damage, fracture and fatigue of ceramicmatrix composites. Springer Nature Singapore Pte Ltd. doi: 10.1007/978-981-13-1783-5

22. Morscher G. N., Singh M., Kiser J. D., Freedman M., Bhatt R. (2007): Modeling stress-dependent matrix cracking and stress-strain behavior in 2D woven $\mathrm{SiC}$ fiber reinforced CVI SiC composites. Composites Science and Technology, 67(6), 1009-1017. doi: 10.1016/j.compscitech.2006.06.007

23. Morscher G. N., Gordon N. A. (2017): Acoustic emission and electrical resistance in SiC-based laminate ceramic composites tested under tensile loading. Journal of the European Ceramic Society, 37(13), 3861-3872. doi: 10.1016/ j.jeurceramsoc.2017.05.003
24. Racle E., Godin N., Reynaud P., Fantozzi G. (2017): Fatigue lifetime of ceramic matrix composites at intermediate temperature by acoustic emission. Materials, 10(6), 658. doi: 10.3390/ma10060658

25. Gao Y. C., Mai Y. W., Cotterell B. (1988): Fracture of fiberreinforced materials. Zeitschrift für angewandte Mathematik und Physik ZAMP, 39(4), 550-572. doi: 10.1007/ BF00948962

26. Solti J.P., Mall S., Robertson D. D. (1995): Modeling damage in unidirectional ceramic-matrix composites. Composites Science and Technology, 54(1), 55-66. doi: 10.1016/ 0266-3538(95)00041-0

27. Snead L. L., Nozawa T., Katoh Y., Byun T. S., Kondo S., Petti D. A. (2007): Handbook of SiC properties for fuel performance modeling. Journal of Nuclear Materials, 371(1-3), 329-377. doi: 10.1016/j.jnucmat.2007.05.016

28. Wang R., Li W., Li D., Fang D. (2015): A new temperature dependent fracture strength model for the $\mathrm{ZrB}_{2}-\mathrm{SiC}$ composites. Journal of the European Ceramic Society, 35(10), 2957-2962. doi: 10.1016/j.jeurceramsoc.2015.03. 025

29. Beyerle D. S., Spearing S. M., Zok F. W., Evans A. G. (1992): Damage and failure in unidirectional ceramicmatrix composites. Journal of the American Ceramic Society, 75(10), 2719-2725. doi: 10.1111/j.1151-2916.1992. tb05495.x

30. Zhang S., Gao X., Chen J., Dong H., Song Y. (2016): Strength model of the matrix element in $\mathrm{SiC} / \mathrm{SiC}$ composites. Materials \& Design, 101, 66-71. doi: 10.1016/j. matdes.2016.03.166 